\title{
Advanced Nanomeasuring Techniques for Surface Characterization
}

\author{
Salah H. R. Ali \\ Engineering and Surface Metrology Department, Length and Precision Engineering Division, National Institute for Standards (NIS), \\ Giza 12211-136, Egypt \\ Correspondence should be addressed to Salah H. R. Ali, salahali20@yahoo.com
}

Received 26 August 2012; Accepted 18 October 2012

Academic Editors: L. Carretero, O. Frazão, H. Matsumoto, and A. E. Miroshnichenko

Copyright (๑) 2012 Salah H. R. Ali. This is an open access article distributed under the Creative Commons Attribution License, which permits unrestricted use, distribution, and reproduction in any medium, provided the original work is properly cited.

\begin{abstract}
Advanced precise and accurate nanomeasurement techniques play an important role to improve the function and quality of surface characterization. There are two basic approaches, the hard measuring techniques and the soft computing measuring techniques. The advanced soft measuring techniques include coordinate measuring machines, roundness testing facilities, surface roughness, interferometric methods, confocal optical microscopy, scanning probe microscopy, and computed tomography at the level of nanometer scale. On the other hand, a new technical committee in ISO is established to address characterization issues posed by the areal surface texture and measurement methods. This paper reviews the major advanced soft metrology techniques obtained by optical, tactile, and other means using instruments, classification schemes of them, and their applications in the engineering surfaces. Furthermore, future trends under development in this area are presented and discussed to display proposed solutions for the important issues that need to be addressed scientifically.
\end{abstract}

\section{Introduction}

Surface metrology became very important in many branches of science and industry. Study of dimensional and surface nanometrology is becoming more commonplace in many applications and research environments as well as data treatments dealing with standardized rules. Therefore, surface characterization using advanced accurate and precise nanomeasuring techniques are important tools especially in the production engineering, tribology, biotechnology, and criminology. Because of this diversification, there are more advanced metrology techniques using stylus, optical, and nonoptical methods used for analyzing the surface characteristics, where each technique has its own specific applications [1].

The ISO technical committee TC-213 in the field of dimensional and geometrical product specifications and verification formed a working group WG-16 to address standardization of areal (3D) surface texture and measurement methods, and to review existing standards on traditional profiling (2D) methods including characteristics of instruments. In 2007, the project of this working group was to develop standards for three basic methods of areal surface texture measurements [2-4]. A line-profiling method used a high-resolution probe to sense the peaks and valleys of the surface topography and produce a quantitative profile $Z(X)$ of surface. Areal topography methods extend the lineprofiling method into $3 \mathrm{D}$, usually by restoring a series of parallel pattern profiles or by some quantitative topographic imaging process. It is important to note that some types of areal profiling methods can sense $Z$-height as a function of both the $X$ - and $Y$-coordinates. Whereas others, can display topographic images with a series of parallel $Z(X)$ profiles whose relative heights along the $Y$-direction may be somewhat arbitrary.

In this paper, novel techniques used such as coordinate measuring machine $(\mathrm{CMM})$, roundness testers, roughness measurement instrument, white light interferometer (WLI), confocal optical microscopy, digital holography, scanning probe microscopy (SPM), and computed tomography (CT) methods are investigated. One of the major challenges when moving to smaller measurements is selecting the suitable metrology technique for the desired measurement. Standardization processes will be probably increased in terms 


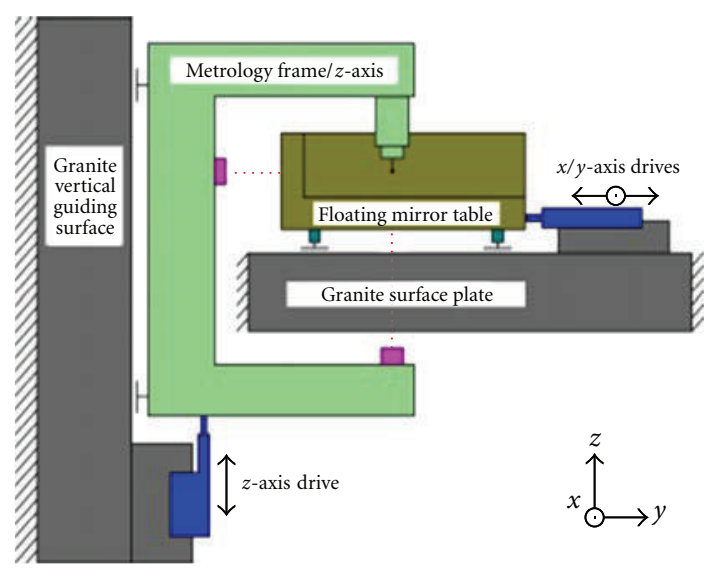

(a) Concept of new CMM

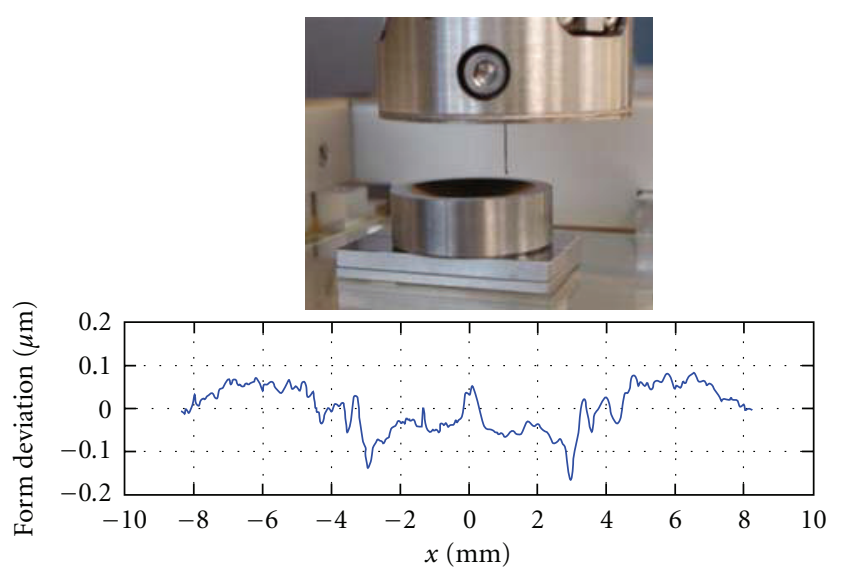

(b) Measurement using the Triskelion probe

Figure 1: New Isara 400 CMM. Figure is taken from [126].

of methods of measurements and data treatments for specific applications due to the externalization and diversification of products. These different advanced techniques have currently advantages meeting the samples specifications and required properties. Therefore, it is important to be aware of how techniques can affect the measured parameters according to specific accurate and precise strategy of measurement. The new applications of dimensional and surface nanometrology in materials science, automotive industry, tissue engineering, and banknote paper will be considered. Moreover, future directions under development will be presented and discussed scientifically in order to introduce proposed solutions for the issues that need to be addressed in the area of interest.

\section{Advanced Nanomeasuring Techniques}

The 3D surface metrology techniques have been rapidly developed in the last decade due to the advanced computational software technology. Mechanical contact stylus, optical, and nonoptical measurement techniques achieved significant progress in many different applications.

2.1. Mechanical Contact Stylus Techniques. The tactile stylus measurement techniques as a coordinate metrology and roundness facilities are powerful tools in modern engineering industries [5-7]. In these techniques, the stylus profiler senses the surface height through mechanical contact, while the stylus traverses the peaks and valleys of the surface with a small contacting force. The vertical motion of the stylus is converted to an electrical signal by a transducer, which represents the surface profile $Z(X)$ or areal topography image $\mathrm{Z}(\mathrm{X}, \mathrm{Y})$. Therefore, the stylus measurement technique is directly sensitive to surface height with little interference. Two disadvantages of the stylus instruments, however, are that the stylus may damage the surface depending on the hardness of the scanned surface relative to the stylus normal force and the stylus tip size [2]. The most important stylus metrology techniques such as coordinate measuring machine $(\mathrm{CMM})$, roundness Talyrond, and surface roughness devices are the three major developed technologies.

2.1.1. CMM Coordinate Technique. Advances in software during the 1980s allowed CMMs to have error corrections and provided geometric computations $[8,9]$. Now, CMM technique is one challenge for advanced coordinate metrology in modern engineering applications. The basic function of CMM is to measure the actual geometrical shape of object compared to desired shape and evaluate the collected data using metrological aspects of size, form, location, and orientation [10]. The actual shape is obtained by probing the surface of the object at definite measuring points. Additionally, the advantage of developed CMM techniques is to convert the data of the measured object into $3 \mathrm{D}$ image suitable for other CAD/CAM systems. Improving the accuracy of CMM measurements is another important issue according to ISO standards. ISO 10360 deals with verifying the performance assessment as specific value of permissible errors for advanced CMM technique $[11,12]$. However, there are two methods used to increase the accuracy of CMMs [13]. The first is based on research and development of design parameters influencing the CMM errors. The most important parameters affecting the CMM errors are the probing system, digital computer with software, and environmental conditions [14-25]. The second development is depending on calibration methods using different devices such as ball plate artifact, hole-plate artifact, and laser tracker.

New generation of advanced coordinate metrology provides ultraprecision CMM with large measurement volume $\left(400 \times 400 \times 100 \mathrm{~mm}^{3}\right)$, Figure 1 . The new Isara $400 \mathrm{CMM}$ is the latest development of IBS Precision Engineering in Netherland. This Isara $400 \mathrm{CMM}$ machine enables coordinate metrology of large and complex parts with nanometer level of uncertainty. The expected length measurement uncertainty is $45 \mathrm{~nm}$, while the full-stroke 3D measuring uncertainty is expected to be $100 \mathrm{~nm}$ at a $95 \%$ confidence level. 


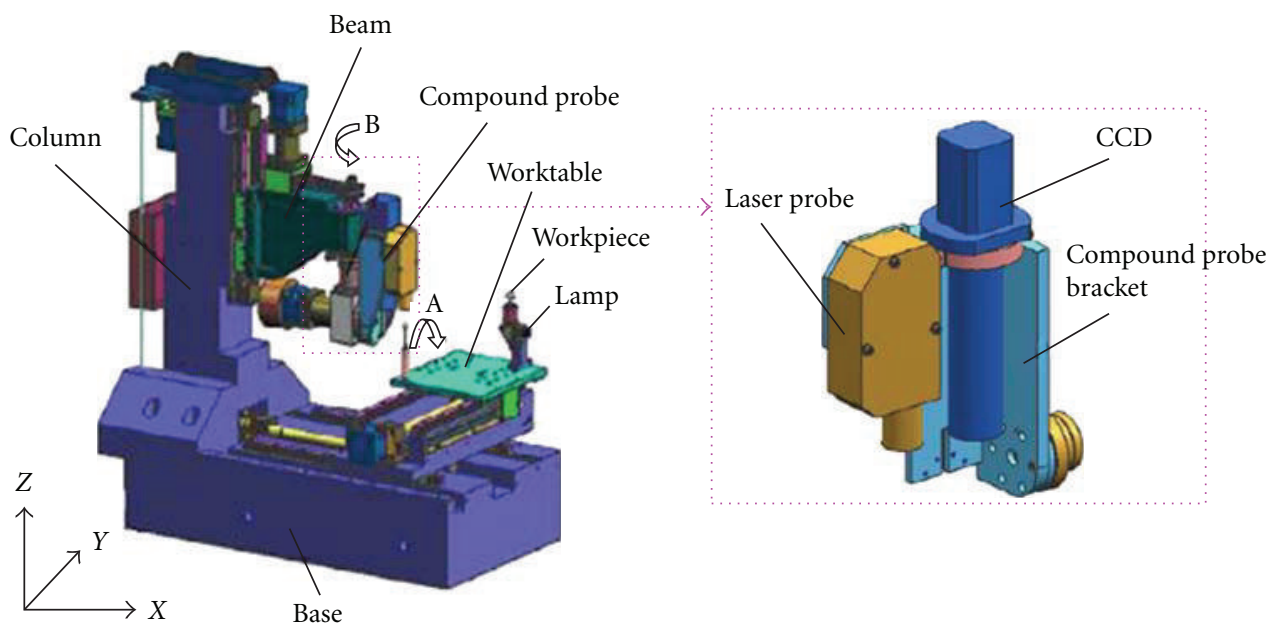

FIGURE 2: The overall mechanical structure of five-coordinate measuring machine and probes. Figure is taken from [27].

Tactile probes, such as the presented Triskelion ultra precision touch probe, as well as other possible (optical) probe systems, can be used to perform scanning at discrete points of object. The presented Isara machine provides a technology that can be adapted and optimized for specific user requirements. However in the future, there is other new trend to produce a new CMM machine with multiple sensors (tactile and optical) in a cooperation research. It will be used in many applications with relative high level of accuracy [26]. On the other hand, the new multisensor CMM has been designed [26]. It is equipped with and incorporates both contact probe and an optical sensor. The profile resolution measuring range is $2.5 \mathrm{~nm}$ and MPE is limited to $250 \mathrm{~nm}$; it is an ideal solution for applications in the plastic industry, medicine and automotive technology, and in precision mechanics when a large number of components have to be measured in short time with at high accuracy.

The future trends in advanced CMM have been discussed. A novel type compact five-coordinate measuring machine with laser and CCD compound probe has been designed and built up as presented in [27]. Mechanical structure and measurement model are introduced. Five motion axes include three translational axes $X Y Z$ and two rotational axes $\mathrm{AB}$ presented in Figure 2. The laser displacement sensor and CCD camera compose the compound probe that can rotate around $\mathrm{A}$-and $\mathrm{B}$-axes while moving along $Z$-axis. The tested workpiece lies on the worktable that can travel along $X$-axis and $Y$-axis in horizontal plane.

The step motors with subdivision function are applied to drive each axis. Among them, the motor for A-axis has contracting brake device which will lock the motor mainshaft and prevent collision of the probe and worktable in case of accidental power off. The high-precision ball screws are applied to drive $X$ - and $Y$-axes. Thus, the related experiments illustrate the characteristics of update CMM machine as well as the feasibility and validity of mentioned methods. Eventually, this area usually needs more dynamic analysis to understand the probe response according to the design and construction of CMMs, especially new hybrid CMM machines [11, 27, 28].

2.1.2. Roundness Instrument. The profile form of the roundness is of primary significance and is an important aspect of engineering surface for cylindrical features, especially in the modern investigations and quality control problems. The development of software analysis tools and their validation is also another major challenge facing the industry. Advanced mathematical techniques are incorporated into such software systems to provide further reference algorithms [29-36]. In this section, two directions of research experiences are reviewed [31-34]. Moreover, new ideas in this area may promote new techniques in the future $[35,36]$.

In Russia, Bogomolov et al. [31] modified the rotating table (Talyrond-200) and rotating gauge (Talyrond73) machines to be automated. These developed systems allowed to apply modern computer-based measurements and analysis of roundness and waviness parameters. Each of the measurement systems consists of analogue roundness machine, analogue-digital converter (ADC/DAC) board, connection cables, and PC with specific installed software. An example of the $2 \mathrm{D}$ roundness measurement results of the component with parametric analysis in software is presented in Figure 3(a). Waviness analysis was provided by proposed measurement systems, which is performed by means of reverting the roundness/waviness filter. Multiple profile 3D analysis of the face side waviness by the measurement systems was also provided as shown in Figure 3(b). The proposed measurement system provides automated highprecision measurements and complex PC-based analysis of roundness and waviness. In this research, inexpensive and powerful automation of both rotating table and rotating gauge roundness machines was performed with the financial support of the Russian federal target program "Academic and teaching staff of innovative Russia in 2009-2013.” 


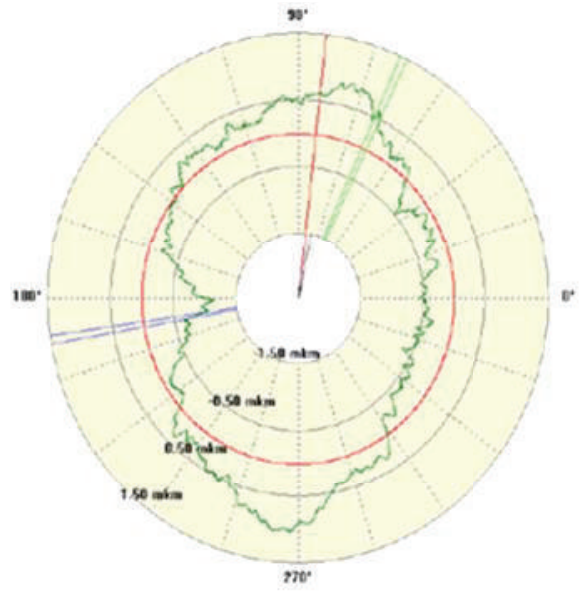

(a) $2 \mathrm{D}$ roundness measurement

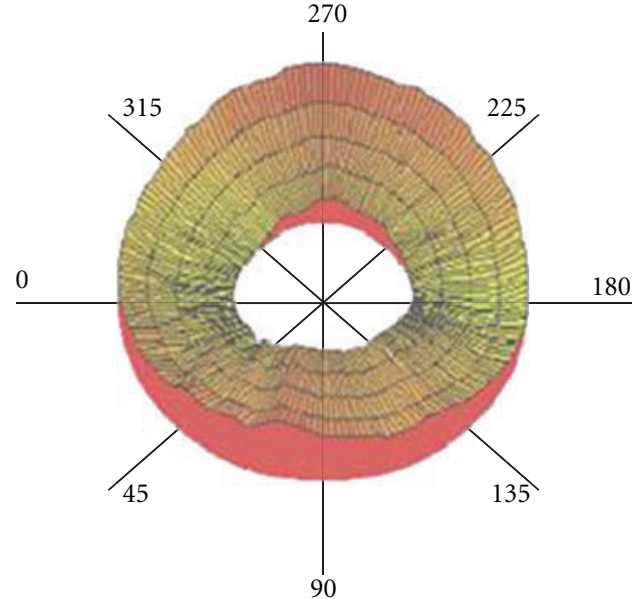

(b) 3D waviness measurement

FIGURE 3: Sample results of developed roundness measurement system in Russia. Figure is taken from [31].

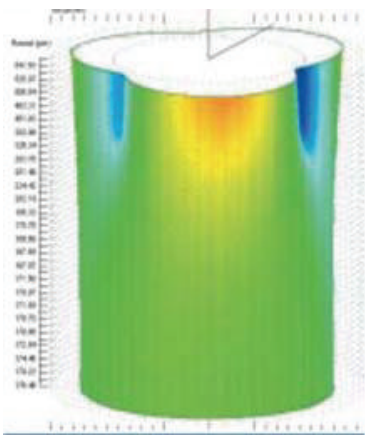

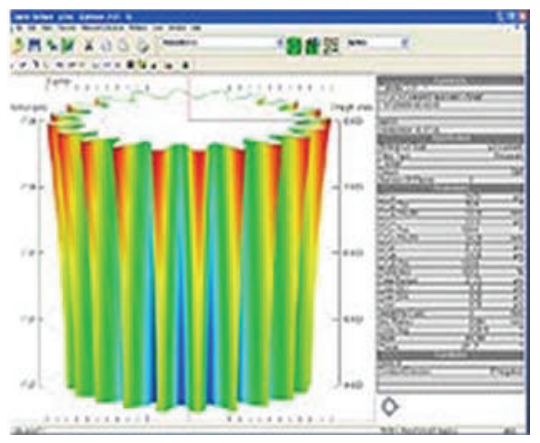

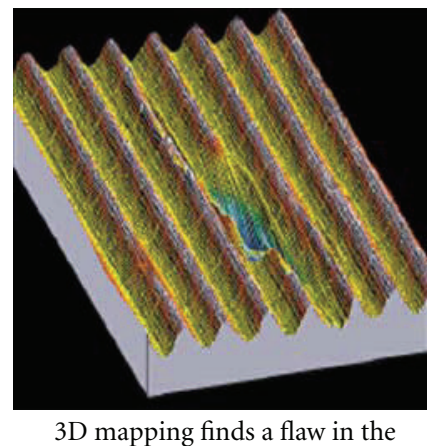

cylinder surface

Figure 4: Results obtained from Talyrond-395. Figure is taken from [34].

In UK from 2000 until now, Taylor Hobson entered a new phase of innovative product design using advanced software [32-34, 36]. Roundness measurements on an automotive fuel injector have been detected using the new Talyrond-365. 2D graph represents the radial variations output from the injector measurements as a polar profile. The circumference measurements showed deviation form that reveals surface roughness and the presence of a scratch that can cause leakage. A scratch is more likely to cause component failure if it is aligned with the component axis. The pass/fail criteria can be programmed and exported to software of the averaged measurement data.

The analysis of structured surfaces, those with repetitive patterns, requires entirely new methods and techniques [37]. Surface-wavelength-based filtering and average parameters will be less applicable in such instance, while discrete feature geometry-based parameters and their statistics over the surface appear to be more relevant. The new wave in advanced $3 \mathrm{D}$ roundness metrology, the design of new ultraprecision Talyrond using ultrasoftware, has been presented $[34,37]$. Figure 4 illustrates the 3D results obtained from Talyrond-395 [34]. These techniques perform as an automatic center and leveling spindle for measuring the workpieces. These that are working dynamically of antivibration mounts combined with the environmental enclosure provide excellent isolation from external influence allowing confident measurement to nanometer level. Talyrond-385 and -395 techniques perform fully automated roundness geometry system incorporating microultrasoftware.

On the other hand, new ideas are suggested for new roundness measurement techniques in the future $[35,36]$. For multiprobes technique, Gao and Kiyono proposed a combined three-point method for on-machine roundness measurements [35]. The roundness measurement system uses three capacitance-type displacement probes as shown in Figure 5. These three probes are fixed around the object to detect the workpiece profile of roundness form, which can be extracted. Spindle error components can be filtered. The combined three-point method not only cancels the effect of the spindle error but also measures roundness profile including the stepwise variation. The feasibility of this proposed method for roundness measurement has been confirmed using PC simulations.

Another idea of noncontact probe has been proposed to measure the diameter and the roundness of turned objects [36]. This research discusses the implementation 

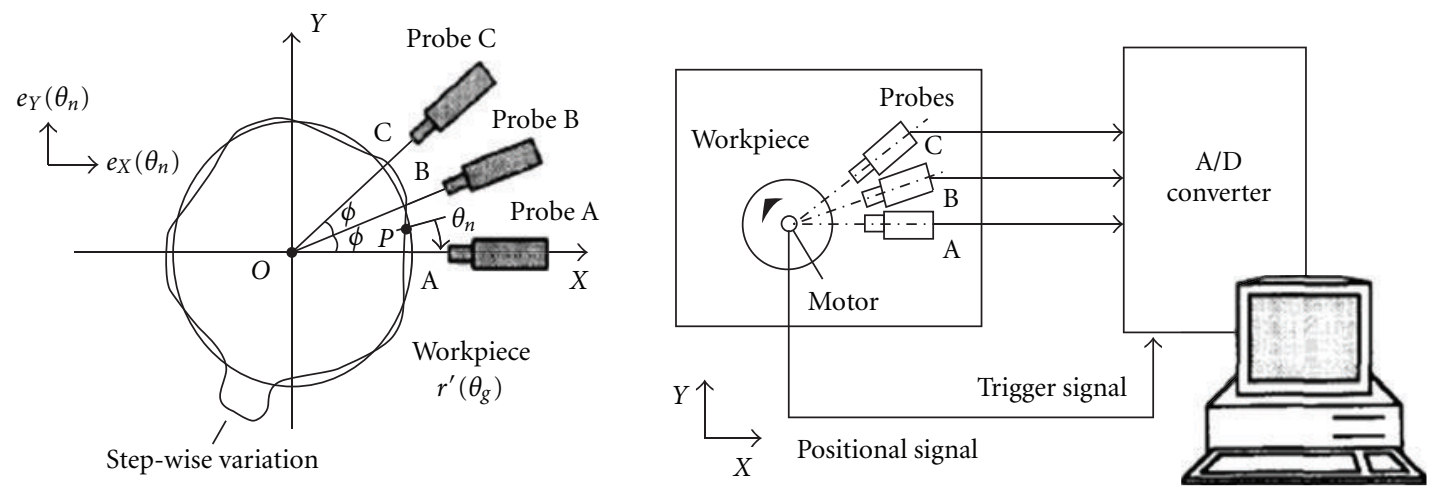

FIgURE 5: Principle of the combined three-point method for roundness measurement system. Figure is taken from [35].

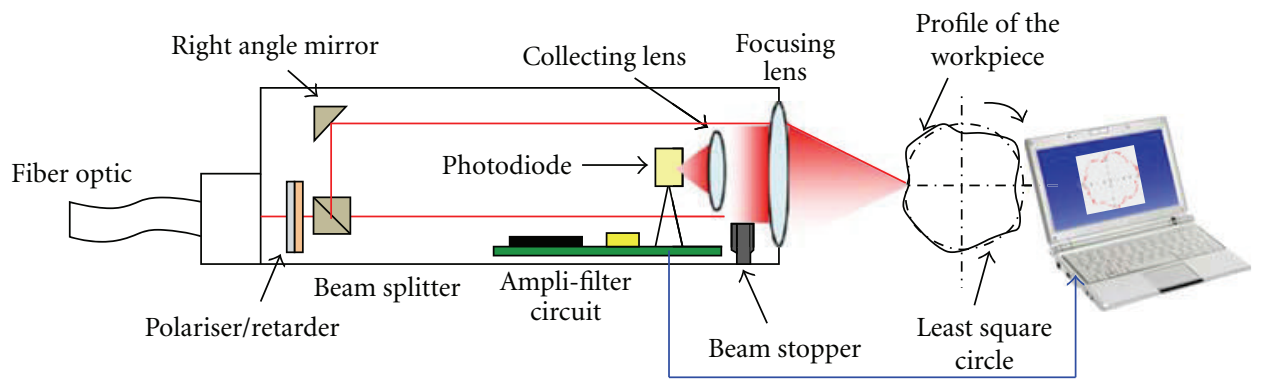

FIGURE 6: The probe configuration for roundness measurement. Figure is taken from [35].

of roundness measurements into the initial probe and its performance. The principle of roundness measurements is based on the fact that the light intensity varies with respect to the displacement from the reflective object. The displacement between the probe and the rotating workpiece may be varying according to the out-of-roundness (OOR) of the object, the error of the rotational system, and the radial throw of the object. The variation of the displacement causes variation of the light intensities reflected from the rotating workpiece. The OOR of the rotating workpiece can be determined by analyzing the variation of the light intensities. The developed probe configured for diameter measurement can be easily reconfigured to measure the OOR of the rotating workpiece by blocking only one laser beam. Figure 6 shows the probe for roundness measurement. All components in the probe configured for roundness measurement are the same as those configured for radius measurement. In diameter measurement, two laser beams are introduced. In roundness measurement, one laser beam is blocked before reaching the focusing lens. A blockage can be placed between the beam splitter and the focusing lens. The laser beam is directed to the object surface. The receiving lens collects the scattered light and focuses it to the photodiode. The intensities of the scattered light are converted to an electrical signal by the photodiode. The electrical signal from the photodiode is sent to an amplifier circuit to eliminate undesired noise and prepare the signal to match the input requirements of the data acquisition (DAQ) system.

The signal from the amplifier circuit converts to the $\mathrm{PC}$ with LabView environment and is processed to extract the OOR of the rotating workpiece. The result shows that the extensive roundness tests have been determined to validate the performance of the probe. The measurements made using the laser-based probe are averages of at least 10 repeated measurements. The out-of-round results were compared with the results obtained from Taylor Hobson. The probe performance gives a maximum error of $0.5 \mu \mathrm{m}$ with an uncertainty of $1 \mu \mathrm{m}$ for roundness measurements. This concluded that the geometrical form of the roundness measurement can be adapted from the radius measurement form. This is a potential capability to add measurement features to the existing probe, for example, surface roughness. The signal obtained from scattered lights using the roundness configuration includes the roundness information and the roughness information.

2.1.3. Roughness Measurement Technique. A profilometer technique was first constructed by Abbott and Firestone's in 1933 [38]. It is known that modern software allows computing of approximately 300 parameters of roughness profile and dozens of topography parameters. Roughness of any surface can be measured up to $200 \mathrm{~mm}$ length and $100 \mathrm{~mm}$ width with the deviation of guide being equal to fractions of micrometers, and further software support of accuracy can be applied.

In this case, the slide can be measured by a laser interferometer and its errors can be collected in the microprocessor system and used for the correction of indication. Besides, the measuring instruments often offer simultaneous 


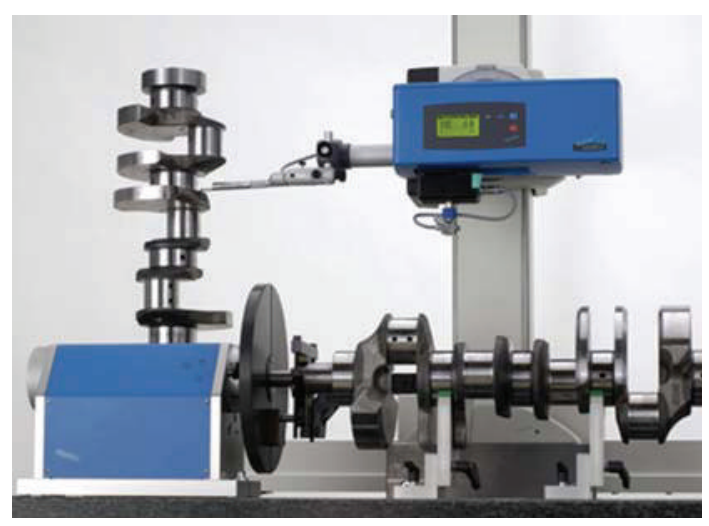

Figure 7: Two modulations of amplitude in roughness measurement. Figure is taken from [39].

measurement of roughness and outline with greater rangeeven above $2 \mathrm{~mm}$ with $0.6 \mathrm{~nm}$ resolution. The interesting element of this device is a probe-magnetically fixed, which prevents damage of any impact or overload applied to the part. The diamond needle is separated from the body on three-point magnetic holder. Additionally, the probe is equipped with an amplitude modulation transmitter and a receiver, which is used for communication with a central processing unit as presented in detail in $[39,40]$, Figure 7. Next possible solution is the application of the measurement probe with bidirectional pressure force up and down. It allows to measure, using the same probe, the roughness on the upper and lower surface of a hole and, in conjunction with an incremental linear encoder in a measuring column, allows measurement of small inside diameters along a vertical axis. It is especially useful in the automobile industry, production of pumps and injectors, where, without fears of probe damage $\mathrm{CNC}$ procedures to measure roughness, waviness and outline in small holes can be used. In another configuration, the application of developed cantilever-type tactile sensor for fast and nondestructive form and roughness measurements has been presented. Fuel injector nozzle comprising spray holes of 170 to $110 \mu \mathrm{m}$ in diameter was characterized at different scanning speeds and probing force. Thus, results of that work proved the potential of the novel sensor for in-process metrology during the manufacturing of injector nozzles $[41,42]$. The tactile sensor has been realized as an extremely slender silicon cantilever integrated with probing tip. When the tip is brought into contact with workpiece during test and moves along the surface, the supporting cantilever is deflected which can be monitored via an integrated piezoresistive strain gauge. The typical profile measured inside the spray hole, obtained by scanning a tactile cantilever sensor tip, which is composed of distinct regions, has been presented [42].

Measurements based on a stylus profilometer in 3D surface topography are time consuming, which is a significant limitation. A possibility of overcoming this inconvenience is spiral sampling [43] as seen in Figure 8 [44]. Irrespective of the contact devices, constructions based on optical phenomena are being developed. Therefore, the optical methods

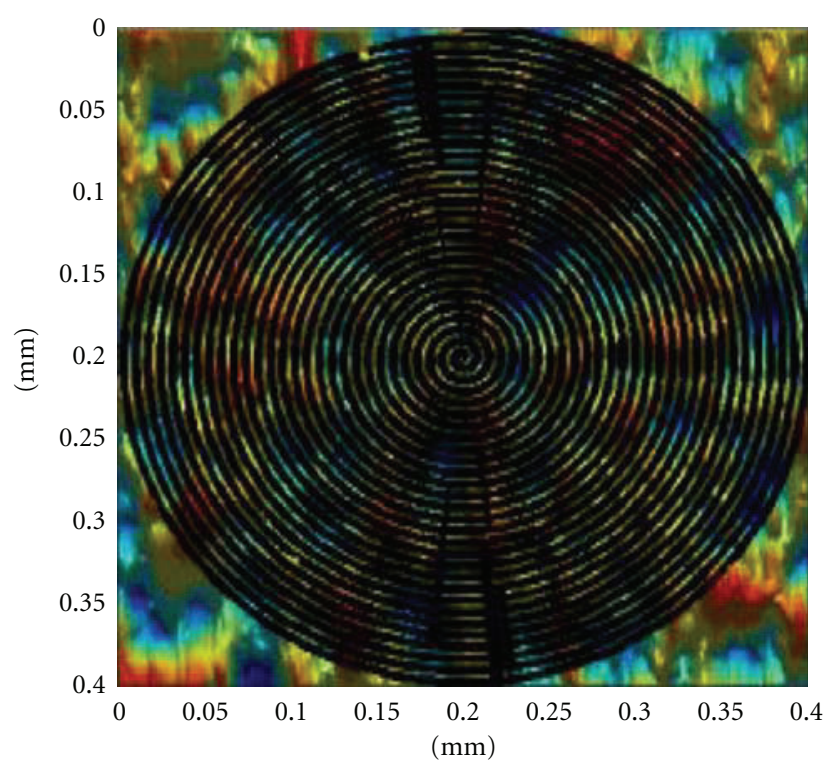

FIGURE 8: Application of spiral sampling. Figure is taken from [44].

have been described in depth in the scientific literature [44-48]. New solutions have introduced CCD (ChargeCoupled Device) lines and arrays to detect the light signal as used in the light scattering methods. These techniques can be used successfully in roughness measurements in preventive inspection, and their vertical measuring range reaches one micrometer $[49,50]$. Modern interferometers, used in roughness measurements, are systems applying white light. The most popular interferometric measurement techniques are phase-shifting interferometry (PSI), vertical scanning interferometry (VSI), and enhanced vertical scanning interferometry (EVSI). PSI uses a monochromatic light source and generally is applied to analysis of a very smooth surfaces, because this method is characterized by subnanometer resolution. On the other hand, it suffers from phase-ambiguity problems, which limits PSI usability to a surface discontinuity not higher than $\lambda / 4$, where $\lambda$ is the wavelength of the light used. Besides, the monochromatic light source limits using PSI to ranges where continuous fringes can be obtained. In order to overcome this difficulty a new technique called Multiple Wavelength Interferometry (MWI) has been developed which has extended highdifference limitation successfully. In this technique, two wavelengths are selected, which allow the user to increase the dynamic range and at the same time to keep the resolution constant. Further increasing of the dynamic range is possible when white light is applied (VSI). Then the continuity of fringes is not so crucial, also more important is finding a focus. The principle of VSI system is shown in Figure 9.

Unfortunately, the resolution of VSI is in the nanometer range, not in fractions of nanometers. The advantages of PSI and VSI are combined in the EVSI technique, also called white light interferometry with phase shifting [51]. Firstly, every pixel was found in the optimal position of the objective for which this point of the surface is in the focus of the optical system, so in this position the distribution of intensity of 


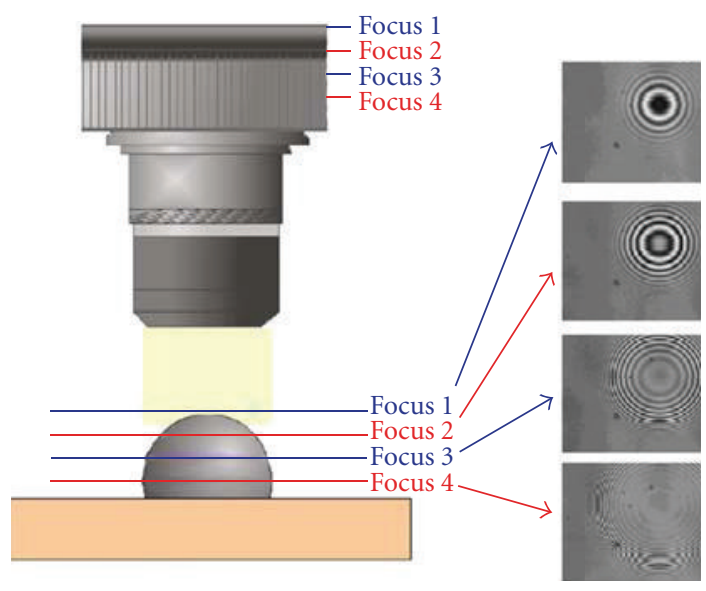

Figure 9: Principle of a VIS Figure is taken from [127].

the interference signal has a maximum. Secondly, to analyze the intensity around the point of focus, a PSI technique is used $[42,51]$.

2.2. Optical Measurement Techniques. Light is at once the most sensitive and the gentle probe of measurement. Light is easy to generate using light-emitting diodes or lasers, and to detect using ultrasensitive photodetectors. Light has become an indispensable nanometrology tool for surface characterization. For these reasons, a number of optical techniques have been developed for line profiling and areal topography. These techniques can provide approaching diffraction of spatial resolution limit. Optical methods have the advantage that they are noncontacting and hence nondestructive tests. Optical methods based on imaging and microscopy also have a higher speed than contacting techniques which rely on mechanical scanning of a contacting probe. However, optical methods are sensitive to a number of surface qualities besides the surface height. These include optical constants, surface slopes, fine surface features that cause diffraction, and deep valleys in which multiple scattering may occur. In addition, scattering from tested surfaces within the optical system produces stray light in the system that can affect the accuracy of an optical profiling method. High sensitive methods, such as phase shifting interferometric (PSI) microscopy have vertical resolution of $0.1 \mathrm{~nm}[52,53]$. By contrast, whitelight interferometric (WLI) microscopy and confocal microscopy have a large vertical range, which is limited mainly by the range of the motion stage used to drive the vertical scan of the instrument and is often of the order of one millimeter.

2.2.1. White-Light Interference Microscopy (WLI). Interferometers and microscopes are combined in interferometric microscopy. Through this combination, very good resolution and significant vertical range can be obtained. Interferometry as a measurement tool is certainly not new but combining old interferometry techniques with modern electronics, computers, and software has produced extremely powerful measurement tools [54-60]. The interferometer is responsible for scanning on a nanoscale, and the microscopy head is

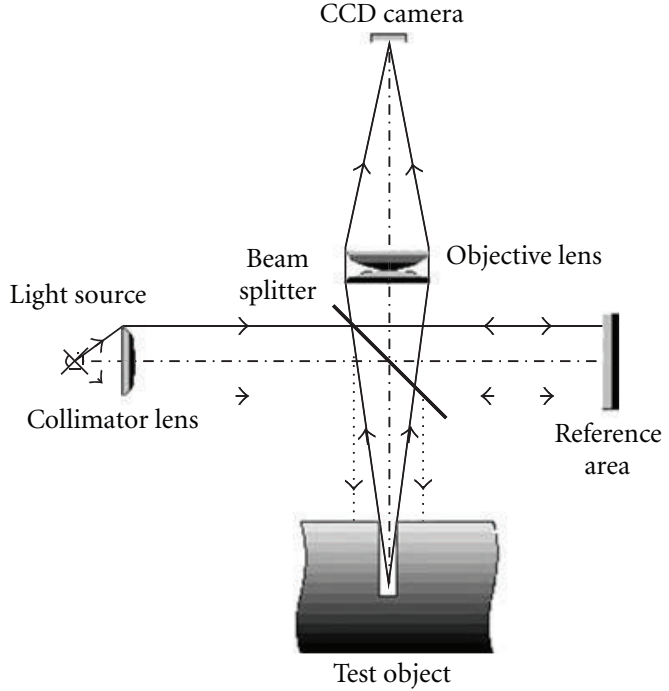

(a) Principle of a WLI. Figure is taken from [69]

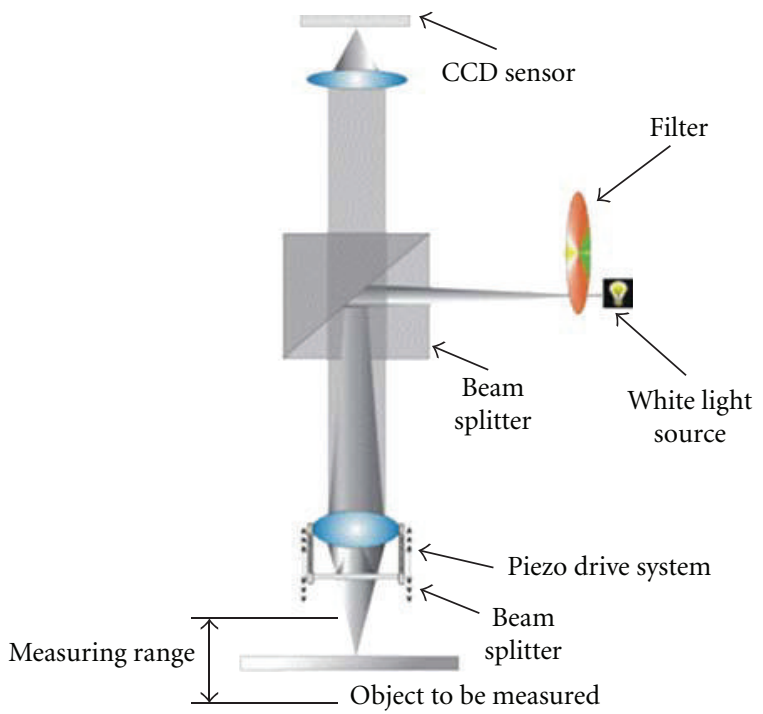

(b) Schematic diagram of setting. Figure is taken from [70]

Figure 10: Principle and schematic diagram of a white light interferometer (WLI) system.

displaced on a microscale giving a vertical range even $1 \mathrm{~mm}$. Descriptions of the operation exceeding and construction of scientific interferometric microscopes can be found in [61, 62]. Typically, there are two different techniques commonly used in phase-shifting interferometry (PSI) and scanning white light interferometry (WLI). WLI microscopy uses a broadband light source [63-65]. The optical system focuses the light through a microscope objective onto a surface. A principle schematic of a scanning white light system [66-69] is shown in Figure 10. The upper beam splitter directs light from the light source towards the objective lens. The lower beam splitter in the objective lens splits the light into two separate beams. One laser beam is directed to the surface of object and the other beam is reflected beam directed to a smooth reference mirror. When the reflected beams are 
recombined, interference fringes are produced around the equal path condition for the two beams. This equal path condition can be detected for each local area of the surface corresponding to each pixel of the camera detector. Scanning the surface vertically with respect to the microscope and detecting the optimum equal path condition at every pixel in the camera result in a topographic image.

White light system is used rather than monochromatic light system because it has a shorter coherence length that will give greater accuracy. Different techniques are used to control the movement of the interferometer and to calculate the surface parameters. The accuracy and precision repeatability of the scanning white light measurement are depending on the control of the scanning mechanism and the calculation of the surface properties from the interference data. Another important factor in WLI system is the interference objective that is used [70-72].

A low magnification objective can be used to look at large areas but the resolution is controlled by the resolution of the detector. Higher resolution images need higher magnification objectives but a smaller area has to be measured. The current lateral resolution limit for white light interferometry is about $0.5 \mu \mathrm{m}$ because diffraction effects limit the maximum possible resolution. Another consideration when choosing an objective is the numerical aperture. The numerical aperture (NA) is related to the angle of the light that is collected by the objective. The higher the NA then the greater the angle that can be measured. Normally the higher magnification objectives have a higher NA. Problems in white light interferometry can arise from the presence of thin films which can generate a second set of interference fringes. The two sets of fringes can cause errors in the analysis. In addition, materials with dissimilar optical properties can give an error in the measurement [70]. Accordingly, the Zygo white light interferometric profilometer offers fast, non-contact, high accuracy $3 \mathrm{D}$ metrology of surface features for a wide variety of samples. The software provides graphic images and high-resolution numerical analysis to characterize the surface structure of materials at magnifications up to 2000X. Maximum vertical range is $20 \mathrm{~mm}$ with a resolution of $0.1 \mathrm{~nm}$ [73].

2.2.2. Confocal Optical Microscopy. Confocal optical microscopy is one of the most widely used advanced techniques in surface metrology. It is called confocal because this type of microscope has two lenses having the same focus point, just as the name might imply. The confocal microscope incorporates the ideas of point-by-point illumination of the specimen and rejection of out-of-focus light. The basic principle of the operation of the confocal microscope is discussed in $[74,75]$; see Figure 11 . The reflected beam reaches to a diaphragm which transmits only focused light and to a photo detector. A vertical scanning system is moving the lens, which allows to analyze different height areas of specimen surface. This ability to distinguish height improves significantly the contrast and the lateral resolution in comparison with the classic optical microscope. Scanning confocal microscopes took advantage of the differentiation

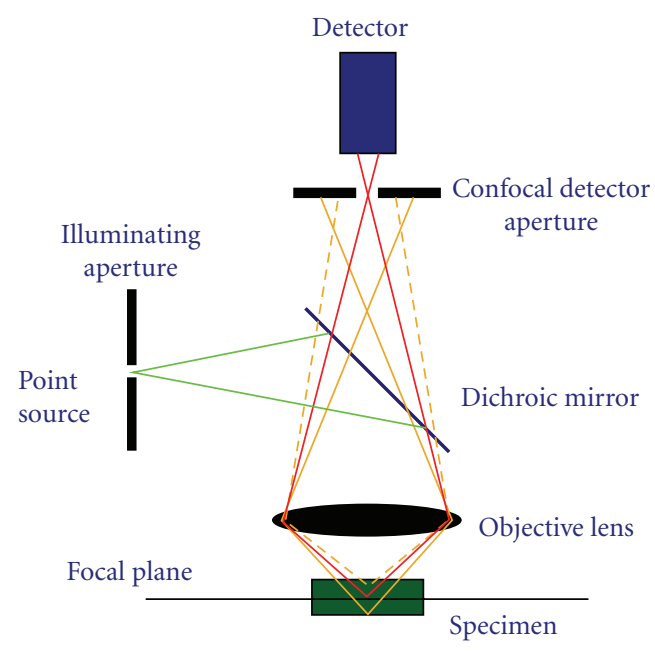

FIGURE 11: The principles of optical system of the scanning confocal microscope. Figure is taken from [128].

of depth and generating of surface image and reception of reflected beam is done by the same optical system. Like in the scanning method, the optical system generates a spot on a surface, and a reflected light beam is recorded by a point detector.

2.2.3. Confocal White Light Microscopy. WLI and confocal microscopy seem good, particularly versatile. PSI is limited to smooth surfaces, whereas the vertical dynamic range of WLI and confocal microscopy extends from the nanometer level (noise) to a large range [65]. In connection with a suitably prepared light beam (after passing through another Nipkow disk with microlenses), it allows a scan of the surface topography effectively. Construction with the confocal head connected to the traditional profilometers instead of the contact head has become more popular in recent years. The light illuminating the surface is usually white light. The beam incident on the surface is split into its spectrum by the passive optical system. Only one chosen frequency which depends on the height of every point is focused on it and gives a sharp image of this point on a photodetector [40]. The photo detector is a precise spectrophotometer which allows to identify that wavelength which gives the information about the height of the surface pattern of the measurement. The scheme of this construction is presented in Figure 12.

Other scanning microscopes are applied to analyze surface of objects. Among these are two families of devices: scanning electron microscopes (SEM) and scanning probe microscopes (SPM). SEMs are used rarely in the investigation of roughness whereas SPMs are becoming more and more popular. SEM is an optical method microscope technique that has been accepted in the nanoscale measurements. It allows to obtain very good vertical resolution. Serious problems appear only in the case of very rough surfaces and the necessity to use a larger vertical range. Microscope application can cause a little difficulty in the interpretation of results of measurement, especially when samples have inclusions or impurities on the surface with different 


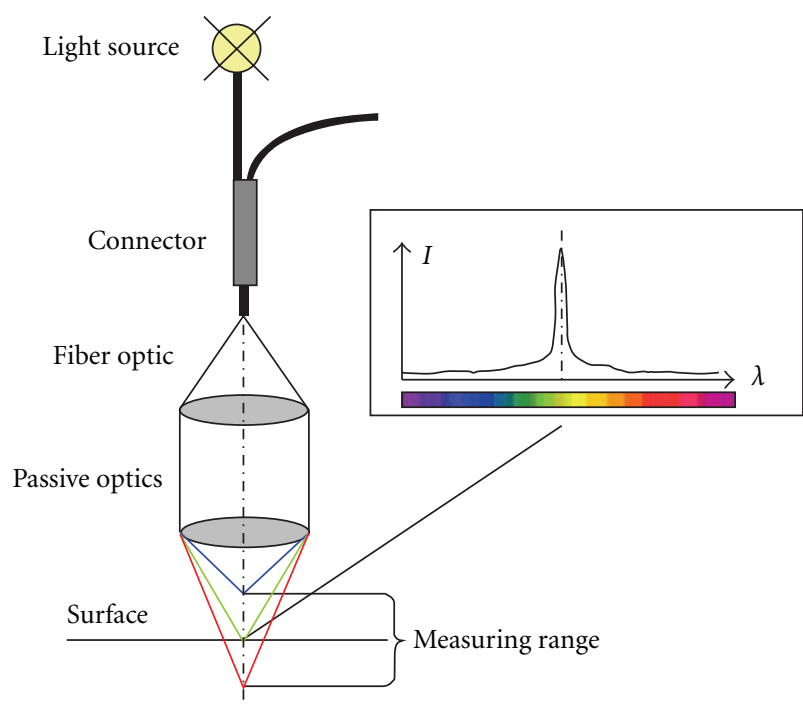

(a) Schematic diagram. Figure is taken from [40, 129]

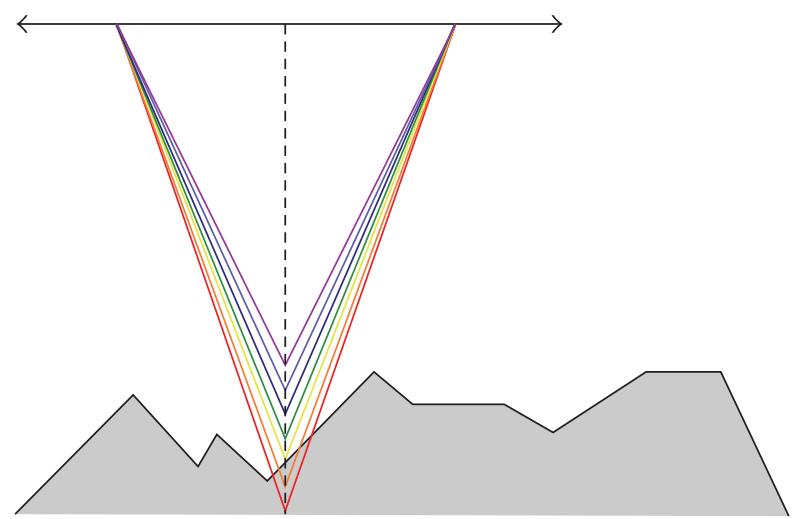

(b) Measuring range principle. Figure is taken from [130]

FIGURE 12: Schematic diagram of a confocal white light sensor for a profilometer.

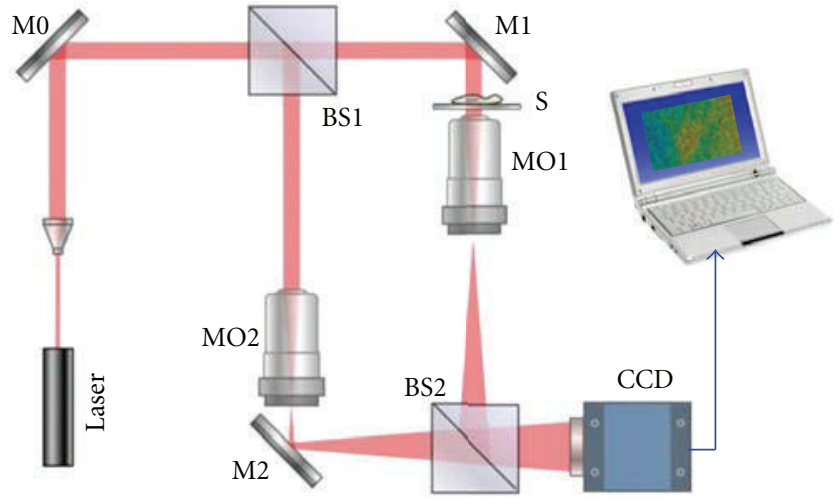

FIGURE 13: Schematic setup of digital holography technique. Figure is taken from [79].

characteristics or can have an influence on the response of instrument.

2.2.4. Digital Holography Technique. Dennis Gabor invented holography as a method for recording and reconstructing the amplitude and phase of a wavefield in 1948. Digital holography $(\mathrm{DH})$ technique is established as an important scientific tool for applications in imaging, microscopy, interferometry, and other optical disciplines [76-78]. The DH setup for recording off-axis holograms is shown in Figure 13, where Ms are mirrors, BSs are beam splitters, MOs are microscope objectives, and S is sample object. DH using is based on collecting data via a CCD camera to investigate surface characteristics in some measurements applications such as engineering materials, and biomedicine such as crack test. It consists of a Mach-Zehnder interferometer illuminated with a He-Ne laser whose wavelength is $633 \mathrm{~nm}$ [79].
2.3. Nonoptical Measurement Techniques. The scanning probe microscope (SPM) is a family of mechanical probe microscopes that scans the object in order to measure surface morphology in areal space with a resolution down to the atomic level [80]. An image of the surface was obtained by mechanically moving the probe in a raster scan of the specimen, line by line, and recording the probe-surface interaction as a function of position. The two primary forms of SPM are scanning tunneling microscope (STM) and atomic force microscope (AFM). SPM was founded with the invention of the STM in 1981 by Binning and Rohrer for which they received the Nobel Prize for Physics in 1986 [81-83]. The STM is based on the concept of quantum tunneling, when the conductive tip is brought very near to the sample surface (below $1 \mathrm{~nm}$ ) and applied bias electrons from the sample can tunnel through the vacuum between sample and tip. This tunnel electron flow is termed a tunneling current. The value of the intensity of this current decreases exponentially depending on the distance between tip and sample. Constant value of the tunneling current is maintained by feedback which controls distance between sample and tip. The STM registers changes in the value of the tunneling current with a constant distance or a change of the distance with the constant current. Besides STM and AFM there are a lot of different types of scanning probe microscopes, which can be classified in four types: optical, thermal, electric, and force. Some of them are not separate types of microscope, but only modifications allowed using different physical forces $[40,82,84-86]$. The scanning tunneling microscope (STM) and the atomic force microscope (AFM) are the two most often used of the scanning nonoptical probe microscopes. The fundamental application difference between these two types of microscopes is that STM can be used only for conductive materials but AFM can be used also for nonconducting materials [84]. The AFM microscope was 


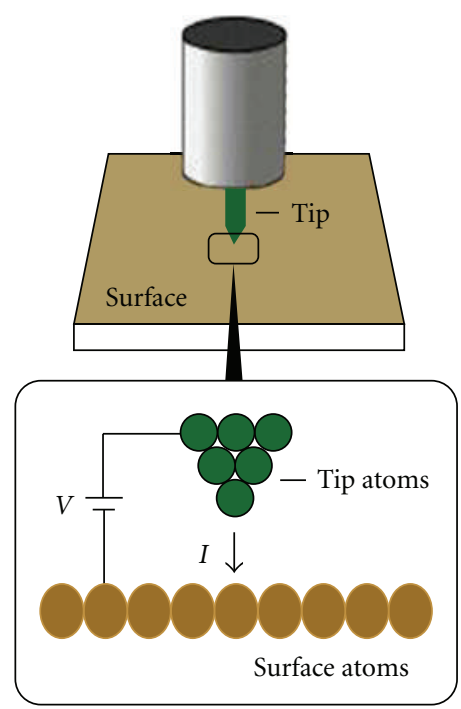

(a)

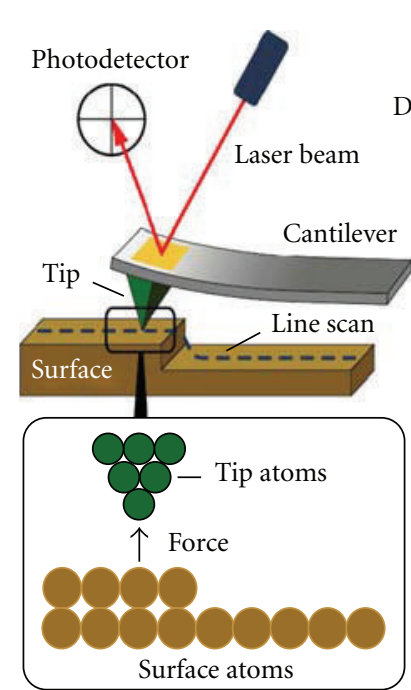

(b)

Figure 14: General principle of STM (left) and AFM (right). Figure is taken from [83].

the first constructed by Binning et al. [82] as a combination of an STM and a profilometer.

2.3.1. AFM Technique. Atomic force microscope is an advanced and important device in the family of SPMs as a nonoptical measuring technique. The principle of AFM operation is based on surface scanning using an elastic cantilever with a sharp tip. The tip presses down to the surface with a small constant force. The tip has height from a small part of a micrometer up to $2 \mu \mathrm{m}$ and tip radius from 2 to $60 \mathrm{~nm}$. Interaction of the tip and the surface is monitored by the reflection of the laser beam from the top of a cantilever on the photodiode detector. Figure 14 shows the basic concept of AFM and STM.

There are some significant advantages of AFM as an imaging tool in surface metrology when compared with complementary techniques such as electron microscopy. In real time, AFM is currently able to achieve surface characterization of engineering nanomaterials and biomedicine more accurate than electron microscopes. AFM works at three different modes: non-contact mode, dynamic contact mode, and tapping (resonant) mode. AFM measures the accurate forces acting between a fine probe tip and surface of an object sample. The tip is attached to the free end of a cantilever and brought very close to a surface of sample. Attractive or repulsive forces resulting from interactions between the tip and the measured surface will cause a positive or negative bending of the cantilever. The bending is dedicated by means of a laser beam, which is reflected from the backside of the cantilever. Figure 15 illustrates the block diagram in $\mathrm{X}, \mathrm{Y}$, and $\mathrm{Z}$ directions at different operation modes of AFM. While scanning the tip across the sample surface (X and $Y$ ), the system adjusts the distance $\mathrm{Z}$ (which is the measure of the height of the sample surface features) between the tip and the sample surface to maintain a constant contact force (contact mode) or oscillation amplitude (dynamic force mode). A 3D image is thus constructed by the lateral dimension, the tip scans, and the height the system measures. Figure 16 shows an example of AFM images obtained on a stamp in the $2 \mathrm{D}$ and the $3 \mathrm{D}$.

2.3.2. 3D-CT Technique. One of the new developed concepts in the last years is the computed tomography (CT) metrology using X-rays. computed tomography (CT) metrology is a technology to measure both internal and external geometries simultaneously in a great variety of parts. Therefore, the CT can be used not only as a simple inspection method but also as a measuring principle capable of providing accurate geometrical information. CT is in the process of revolutionizing quality engineering in industry [87-89]. The Metrotom CT machine together with Calypso software are able to provide also internal and external 3D modeling of the measured part. The basic components of CT technique are illustrated in Figure 17.

The CT machine consists of an X-ray source, a translational movable rotary table where the part to be scanned is placed on an X-ray detector, and a processing unit (composed by 6 processors working together) to analyze and display the measurement results, Figure 18. Currently two different types of CT systems exist depending on the beam and detector types [90, 91]. The 2D-CT systems use a fan beam and a line detector, whereas the 3D-CT systems utilize a cone beam and an area detector. In the case of the Metrotom CT machine a $1024 \times 1024$ pixel $(400 \times 400 \mathrm{~mm})$ in size area detector is used, so that $3 \mathrm{D}$ information can be measured with one revolution of the part. During the measurement processes the radiation which is not absorbed by the object is transmitted and recorded by the detector. For every angle rotated by the table, a new projection is obtained. Once a complete revolution takes place, the processing unit numerically reconstructs the measured object and provides a $3 \mathrm{D}$ graphical reconstruction. 


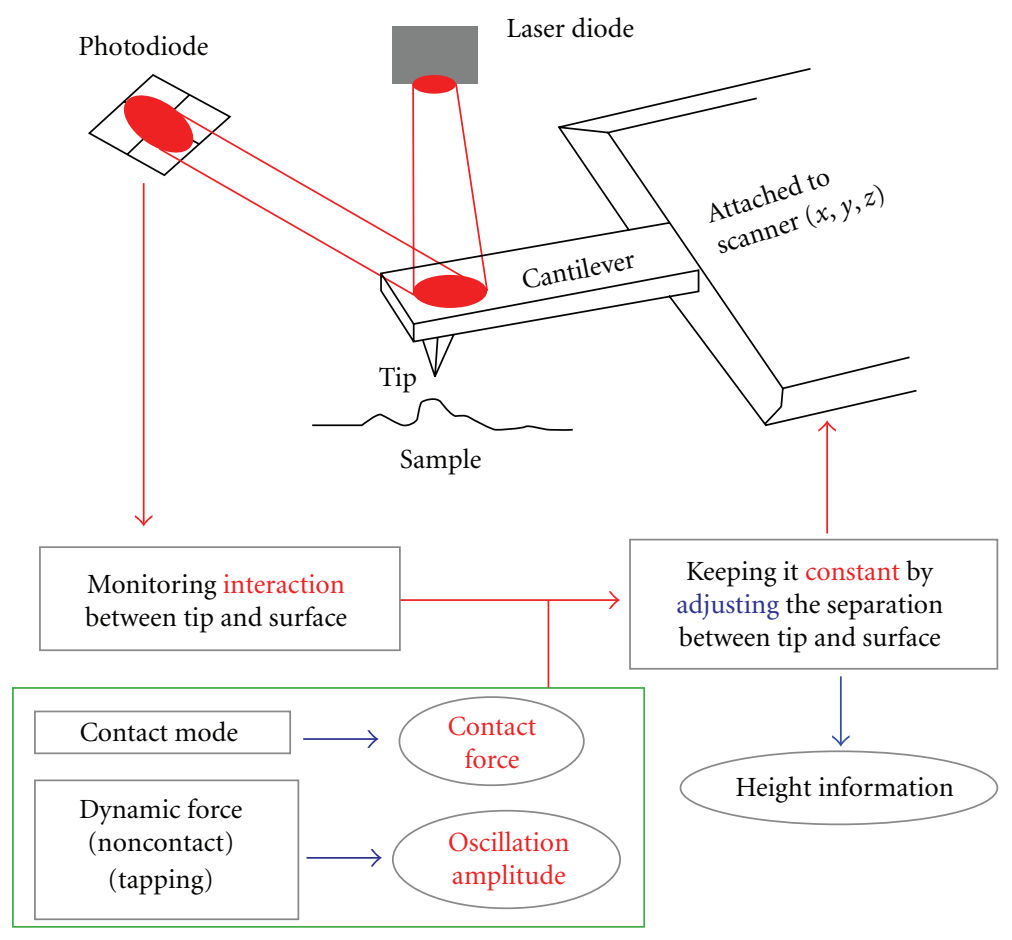

FIGURE 15: Operation of AFM system control loop. Figure is taken from [86].

The primitive elements of the 3D data structure called voxels (volumetric pixels). Identification of surfaces using the CTsystem makes it possible to determine coordinates of the measured part. Therefore, it is able to perform dimensional measurements like CMMs [88, 89].

CT technique provides an enormous amount of information and makes components transparent in the true sense inspection of machine spare parts. Several sources of error [88] can be associated to the detector properties, such as its lateral resolution, energy-dependent sensitivity (regulated by a gain ratio parameter), signal-to-noise ratio, dynamics, and so forth. The main errors are due to failed pixels that can be detected by an adequate calibration of the detector. The part itself is an important source of error from different points of view. Initially it must be adequately tighten to the rotary table. The roughness and cleanness of the part are important issues. The thermal expansion coefficient and the temperature during the process must be taken into account in the compensation part of the measurement software. The geometry and the thickness of the part have important influence on the quantity of radiation absorbed by the part, which can be different from the expected. The material composition will mainly determine the energy-dependent absorption (beam hardening), obtaining better results for materials absorbing less radiation (e.g., plastics). If the measured part is composed of a diversity of materials, unexpected and important effects can be obtained. The changes in the environmental conditions (vibrations, temperature changes) must be, of course, controlled and the system should be isolated from them as possible.

\section{Overlapping, Limitations, Sampling, and Filtering of Existing Techniques}

3.1. Overlapping. Over the past years, many metrological techniques of dimensions and surface measurements have matured and evolved as presented in Section 2. Consequently, the resolution overlapping between these instrumentation techniques have been shown in Figure 19.

It is obvious that there are conjoint area between the measurement techniques, which span a wide range and resolution. This indicates that there is generally a measurement solution for a wide variety of applications, including most that might be encountered in the engineering industries and applied technologies. The overlap between dimension and surface instrumentation techniques produces important benefits such as the following.

(i) It provides competition between different technological techniques.

(ii) It allows for a broader selection of instruments.

(iii) It provides means for comparison.

3.2. Limitations. The limitation keys of existing techniques are miscellaneous. Categories of the optical techniques are sometimes slightly artificial, not as in the case of the mechanical contact stylus techniques. Instruments which are the combination of several techniques have been created more frequently recently. It allows to broaden the measurement range significantly while keeping very high resolution. An example of this solution is the interferometric microscope. 


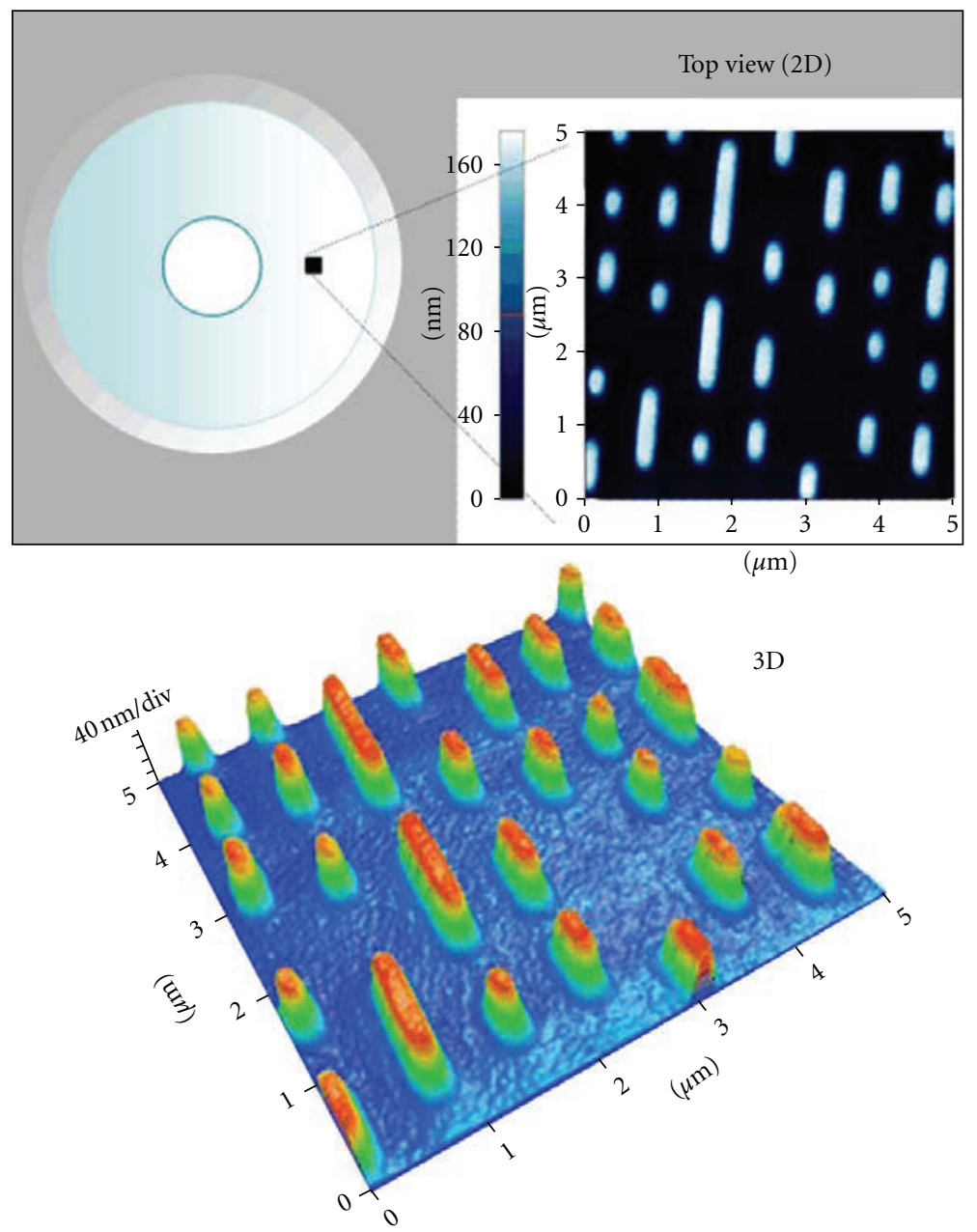

FIGURE 16: AFM image result in 2D and 3D. Figure is taken from [86].

General treatment of optical methods is very cautious while on the other hand the classic profilometric methods are used confidently. This situation is not incidental and results from many factors, for example, application of the optical methods is sometimes questionable due to the fact that the estimation of the object surface the whole mathematical models based on some assumption are used instead of using the surface itself. Moreover, results obtained from the optical methods depend sometimes on physical properties of the surface. In metals, for example, reflectivity is the significant parameter in contrast to some other materials where it is much lower; sometimes it is so low that a large amount of the incident light penetrates the material [40].

In the case of the layered surface, multiple reflections on different layers may occur. Diversity of the penetrations influences the optical length path and changes test results. The presence on the surface of elements which randomly disturb the light path, for example, small radius of curvature, microcracking, or microholes, might be another reason for the abnormality. Further, the optical techniques cannot always be compared with stylus detection techniques, which sometimes make comparison of test result impossible.
Based on a number of comparative analyses some practical limitations for stylus and optical techniques have been determined [40, 92, 93]. Schwenke et al. discussed the differences between both of the technical limitations and the metrological characteristics of the methods [94]. Optical techniques like stylus methods require the isolation of devices from the external environment. Both thermal effects and vibrations have influence on reliability of the result. Very careful cleaning of the sample surface is necessary from the point of view of industrial application. In summary, each device has its specific strategies in operation of measurement to avoid these limitations as much as possible.

3.3. Sampling and Filtering. Data collected from measurements is the starting point for many processes and may be used in different ways [40]. The data process of analogueto-digital conversion, called digitization, amounts to the representation of the continuous analogue signal by discrete data. In the frequency domain, the values of signal are recorded at equal intervals in the plane of the surface. This process is called sampling. If the sampling interval is too small, the data are highly correlated and a large number 


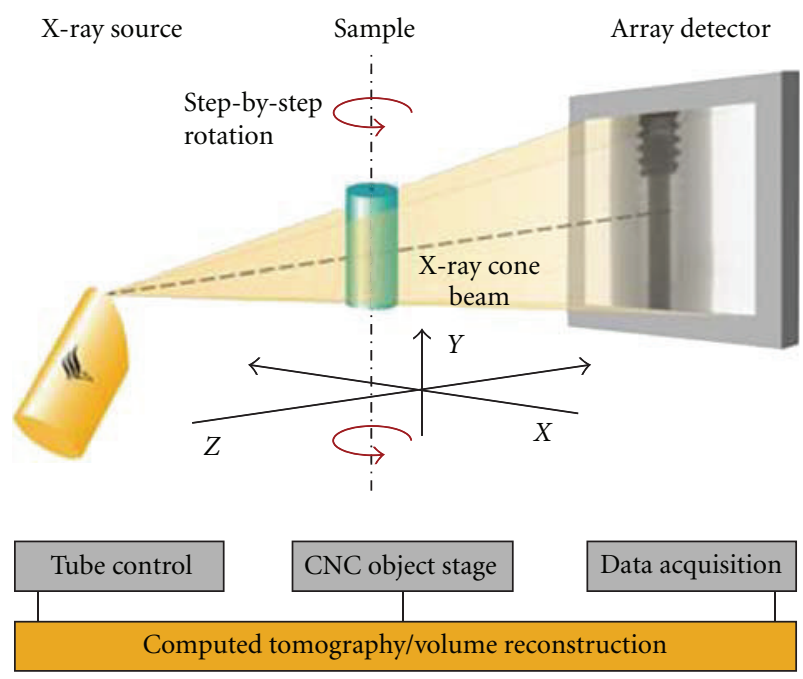

FIgURE 17: Principle operation of CT technique. Figure is taken from [131].

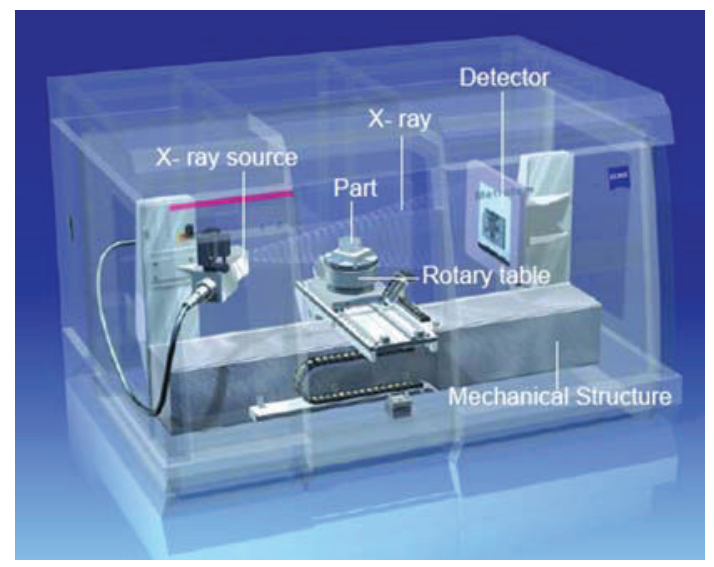

Figure 18: Components of Metrotom CT. Figure is taken from [88].

of data points are required to represent surface topography. If it is too large, the resulting data are highly uncorrelated resulting in loss of surface spatial information (aliasing). In $3 \mathrm{D}$ stylus measurement, the sampling interval should be as large as possible, because measurement time (comparatively long) depends on it. An assessment of surface topography by parameters is useful when long wavelength components are removed from the measured surface data. The unwanted elements of the surface geometry are commonly referred to the waviness, due to imperfections in the manufacturing process. A necessary preliminary to numerical assessment of surface profiles is to extract the frequency components representative of the roughness and to eliminate those that would be irrelevant. A Gaussian filtering technique has been adopted for the filtration of surface topography. The Gaussian filtering technique solved the problems of phase distortion, but edge problems still exist in Gaussian filtration (marginal running-in and running-out lengths, where roughness and waviness parameters cannot be calculated). The performance of the Gaussian filtering technique is

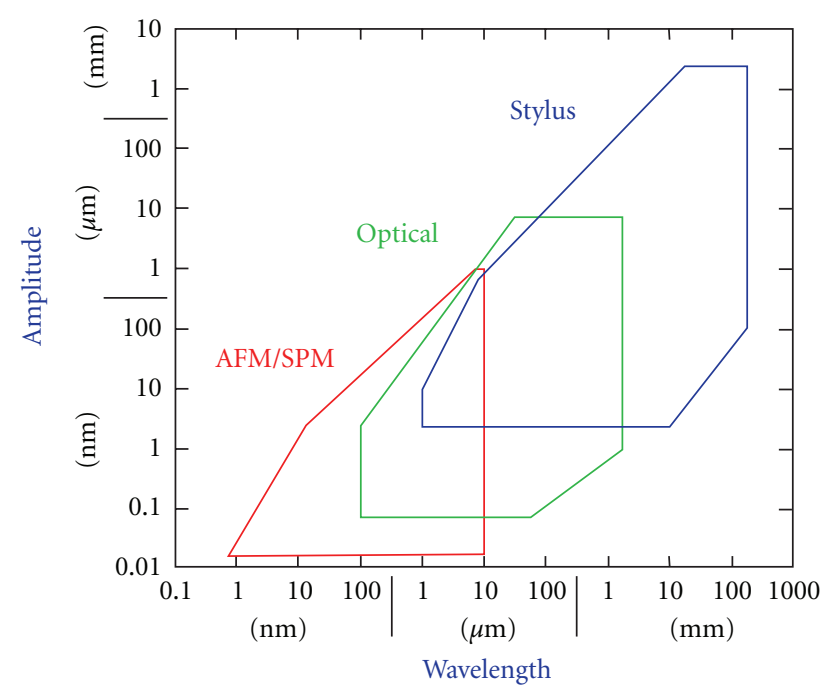

FIGURE 19: Steadman diagram showing the range and resolution of dimensional measurement techniques (mechanical stylus, interferometric optical microscopes, and AFM/SPM). Figure is taken from [132-134].

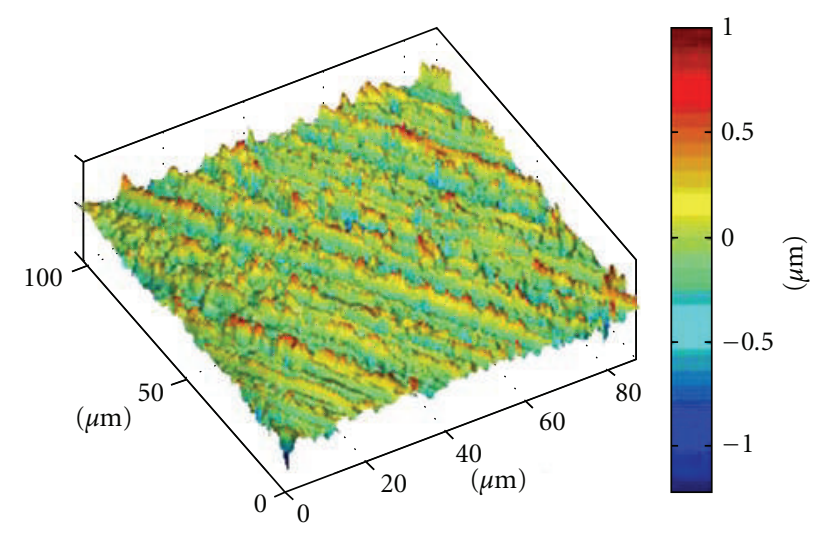

FIGURE 20: Plateau surface roughness using developed WLI technique. Figure is taken from [98].

affected by certain conditions, especially for surfaces having freak signals (outliers) such as grooves, scratches, and scores. Multiprocess textures are an example of such surfaces. The problem is that control of such surface texture requires a complementary response from surface metrologists. Without adequate measurement technique the control, and hence any attempt to maintain quality, is lost. Therefore, there are many research efforts to study the effects of sampling and filtering of dimensional and surface metrology methods.

\section{Surface Characterization}

Many different applications in the dimension and surface characterization using advanced nanometrology techniques, whether 2D and 3D, in both micro- and nanometer scale can been presented. Many works present some new and promising approaches that may play an important role in industry and different other applications using advanced metrology 


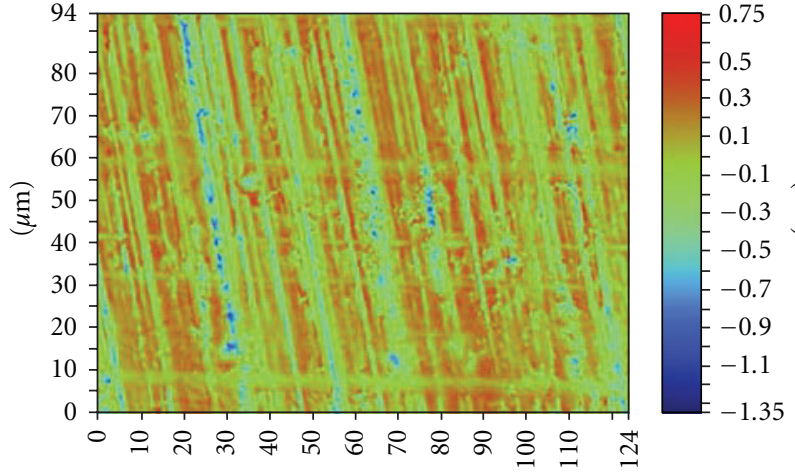

$(\mu \mathrm{m})$

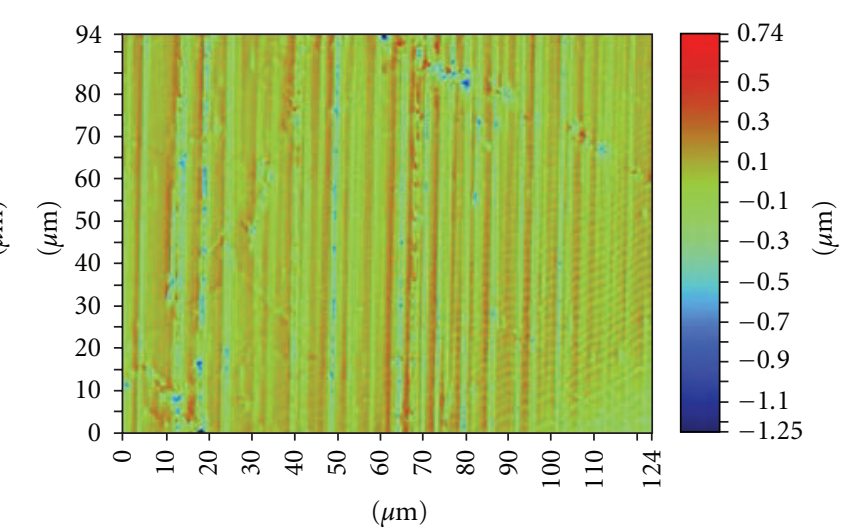

$(\mu \mathrm{m})$

(a) Engine piston ring (unworn section left, worn section right)
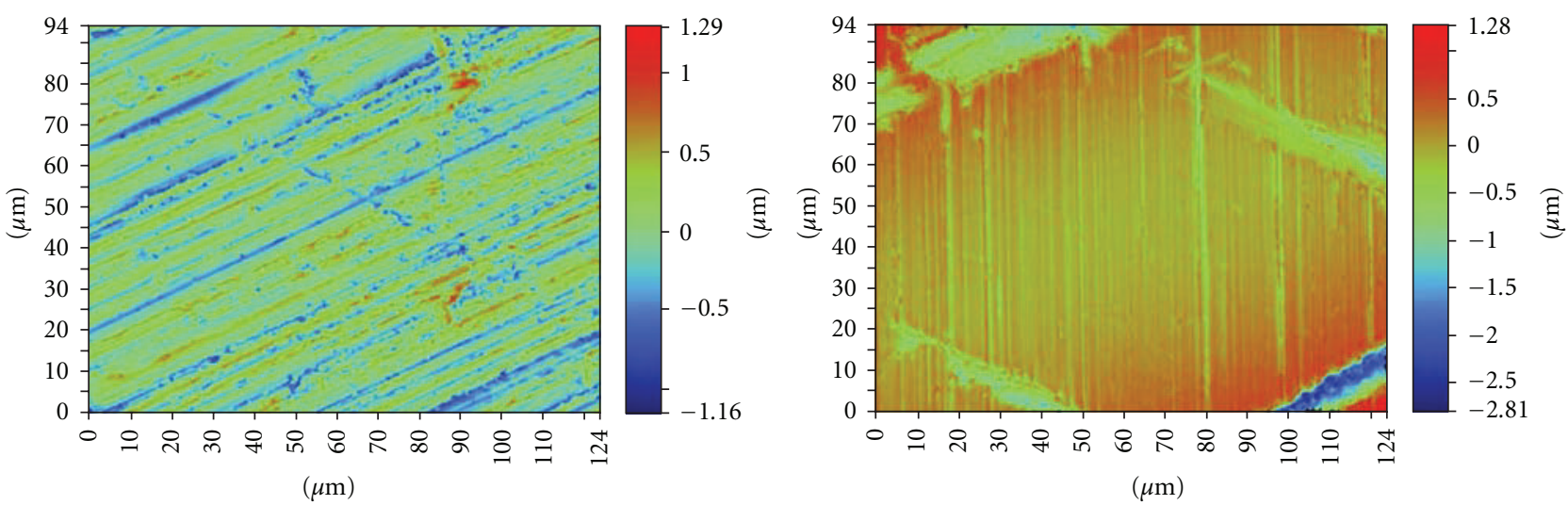

(b) Engine cylinder liner (unworn left, worn right)

FIgURE 21: WLI images of (a) piston ring and (b) cylinder liner. Figure is taken from [108].

techniques. Thus, the macroengineering applications and surface porosity in the micro- and nanoscales have been presented.

4.1. Applications in the Mechanical Engineering. Surface metrology in mechanical engineering must be fast, accurate, robust, automated, and ideally integrated into the production line or product assessment, especially in materials science and automotive industry. With regard to the applications, CMMs offer a complete range of metrology solutions for many inspection tasks in different fields, in automotive industry and tribology. Some applications in CMM have been developed over the last years. The most familiar and earliest commercial application of surface texturing is that of automotive engine cylinder liner as a critical metallic element. Inspection programs of mechanical designated parts in automotive desiel engines the processes of measuring their dimensional and geometrical features has been developed and presented in [95, 96] at NIS by the author of this work et al. The results of bore diameter and roundness deviations as assessed of the four cylinder liners of the test engine under investigation at twelve locations along the effective traveling stroke using CMM have been displayed in [95] using fraction of $\mu \mathrm{m}$.
The topography of surfaces is commonly used to analyze surfaces after different operations and/or machining processes. The most familiar and earliest commercial application of surface texturing is that of automotive engine cylinder liner as a critical metallic element. At first, the recommended cylinder surface after honing was very smooth since it showed high wear resistance during running-in. Considerable progress in engine construction causes a great scuffing inclination of the smooth cylinder surface. Only rough surfaces have a higher load-carrying capacity. Running-in wear studies was conducted by the authors of [97]. Compression ignition engine showed that the linear wear of the cylinder increased with the increase in its initial surface roughness height. Rough surfaces wear rapidly without seizure during running-in period to promote quick performance, so an initial surface finish of the cylinder of $0.8 \mu \mathrm{m} \mathrm{Ra}$ (centerline average roughness) is recommended. Recent published work presents surface texture as a real measured area of plateau roughness within the maintained $\mathrm{Ra}$ value as illustrated in Figure 20 [98].

The topography of engineering surfaces is commonly used to analyze surfaces before and after operation processes. The applications of texturing include pistons, brake discs, bearings, mechanical face seals, gas seals, hard disk sliders, machine tools guideways, and other elements. One can 

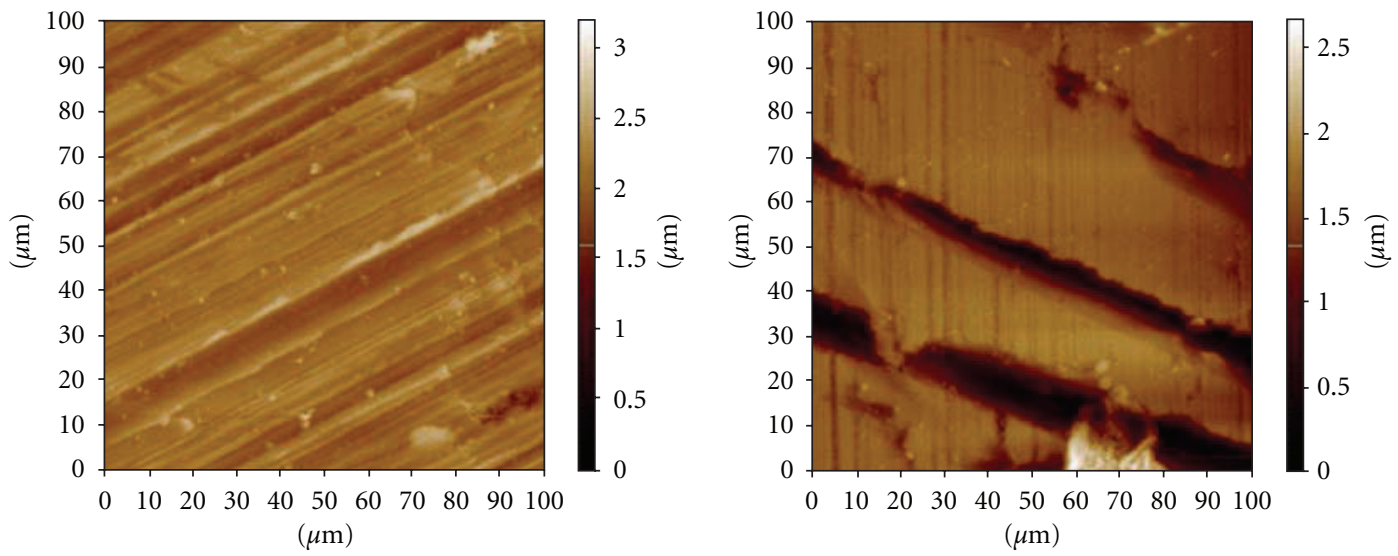

(a) Engine piston ring (unworn left, worn right)
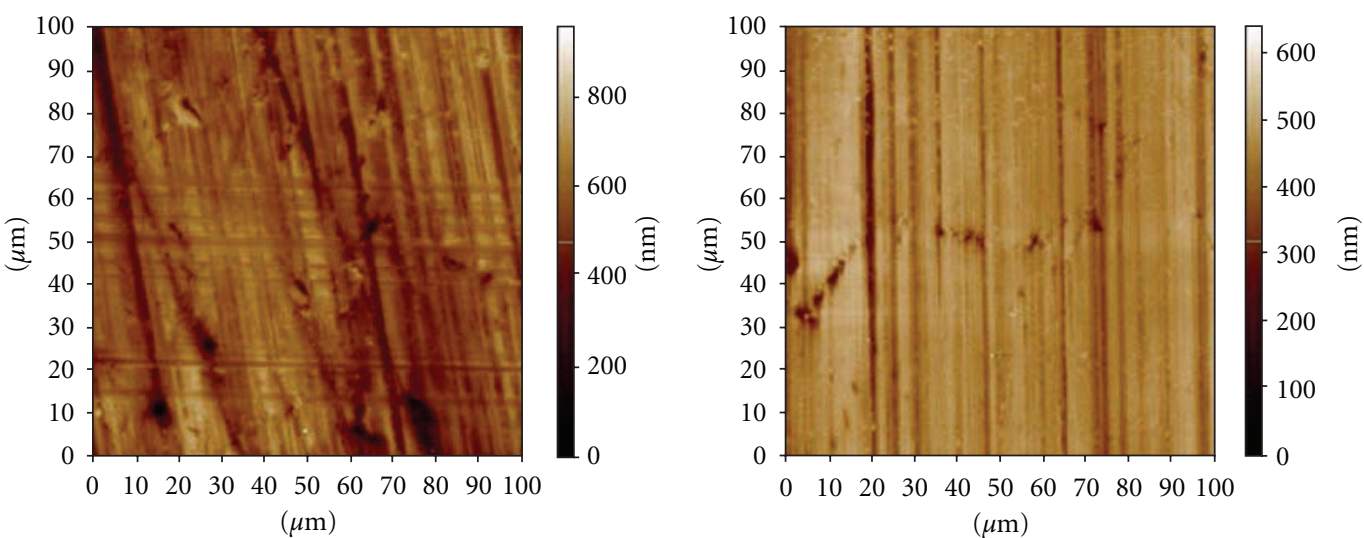

(b) Engine cylinder liner (unworn left, worn right)

Figure 22: AFM images of (a) piston ring and (b) cylinder liner. Figure is taken from [108].

find recent publications presenting profitable effects of surface texturing on seizure resistance in [99-101], transition between fluid and mixed lubrication in [102-104], and wear resistance in $[105,106]$. The study of texturing usually requires multiscale analyses; therefore, frequently different techniques have been used [107, 108].

The cylinder liner and piston top compression ring have been both measured both with an atomic force microscope (AFM) and white light interferometer (WLI) [108]. Two different techniques are employed so that the effect of measuring technique on the results can be assessed. Figure 21 shows typical measurements for the four surfaces. The sliding motion in these images is in the vertical direction.

The piston ring is chromium coated and exhibits little wear apart from some minor scratching and smoothing in the direction of sliding. The cylinder liner is made of much softer cast iron and becomes markedly different after having been worn in the engine. The plateaux have been massively smoothed leaving the deep honing grooves clearly visible. Typical measurements for the four surfaces are given in Figure 22. A similar trend of wear can be visually observed in the AFM measurements as for the WLI measurements.
4.2. Other Applications. Many other applications using surface metrology are presented. These fields of applications as road surface irregularity, architecture art tools, banknote paper, and biomaterial with tissue engineering using dimensional and surface metrology techniques have been studied and analyzed. Thus, the inspection of concrete structures as a transportation infrastructure investment is a major part of roads management using surface metrology.

In surface metrology, macrostructural application using SEM micrographs has been presented by the author of this work et al. in $[109,110]$. The objective of this paper is to investigate the influence of doped and dispersed CNTs in polymer matrix on its intrinsic properties. Three different types of polymers, polyvinylchloride (PVC), polymethylmethacrylate (PMMA), and polystyrene (PS), were subjected to this experimental investigation. CNTs/polymer matrix composites with a content ratio of CNTs up to $5 \%$ by weight were synthesized.

Figure 23 shows the SEM images of CNTs dispersion in three different types of polymer matrix composites. The apparently homogeneous dispersion and the strong interfacial bonding and cross-linking between CNTs and PS polymer matrix are obvious. The functionalized knit-like 

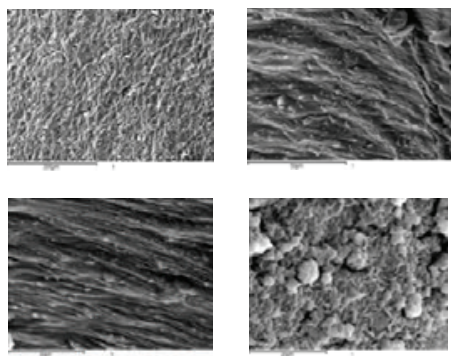

(a) CNTs/PVC
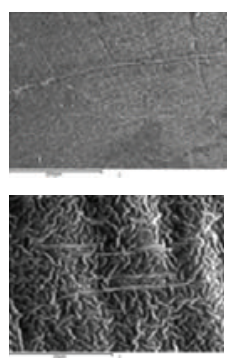

(b) CNTs/PMMA
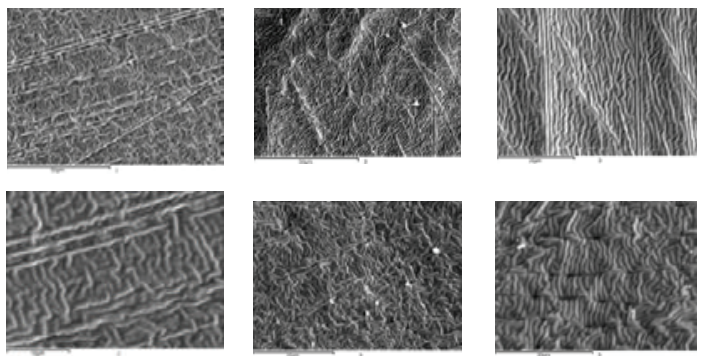

(c) $\mathrm{CNTs} / \mathrm{PS}$

FIGURE 23: SEM images for nanocomposites. Figure is taken from [110].
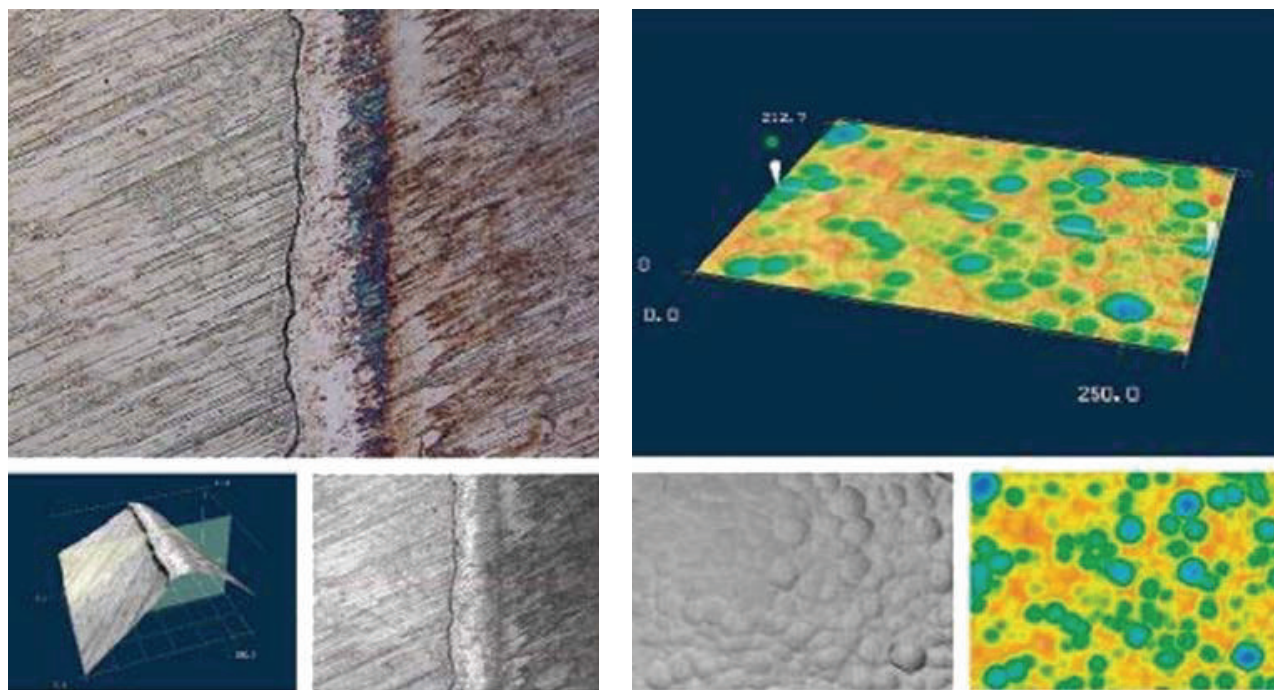

FIGURE 24: Various results obtained by using LSM. Figure is taken from $[111,112]$.

interweave appearance indicates how CNTs play a role as a reinforcing agent in the PS matrix. It can be concluded that CNTs suit well the PS polymer matrix for synthesizing competent composite for different applications. The results of the thermal analysis of the CNTs/PS composites together with its FTIR spectrum, discussed before, confirm this matching phenomenon of the CNTs and the PS polymer. It can be concluded that both PMMA and PS polymers disclosed much better matching ability and cross linking ability with the interweaving CNTs than the PVC. Both PMMA and PS polymers may thus be nominated for further extension of the investigation to cover a wider range of CNTs content ratios in an endeavour towards searching for maximum specific performance properties of such nanocomposites.

Surface roughness of an architecture artist tool has been studied using laser scanning microscope (LSM) technique $[111,112]$. An advantage of LSM is that it uses a fine linear scale while obtaining the measurements. The linear scale is of 0.001 micrometers. The LSM has applications in various fields, mostly when we want to measure roughness or get information on color intensity. The two figures below show two different applications of LSM and give an idea about the result a user might receive upon using this microscope.
The image on the left in Figure 24 is a roughness measurement of a tool blade edge. Even though, it can be actually seen from the results of the LSM measurements that there is a variance on the roughness. The same applies to the figure on the right, where author have measured the roughness of a silicon wafer. Again, silicon wafer appears completely smooth.

Surface topography analysis is often used in the paper and banknote industry. Because of the delicacy of the investigated surface, stylus measurements are replaced by other techniques mainly based on light scattering, although acoustic sensors [113] or AFM are also used. These methods allow for testing of paper for special applications, analysis of old prints and marks of physicochemical impurity, or analysis connected with the deposition of a drop of ink from the printer. Roughness of the paper has influence on the deposition of the ink component, which causes nonuniformity of color printing [114]. On paper with higher roughness uniformity and quality of printing are worse. Figure 25 shows a surface of rough paper. Application of the topography parameters of the surface allows to ascertain that surfaces with similar values of some parameters may have totally different appearances and performances. Besides overprints 


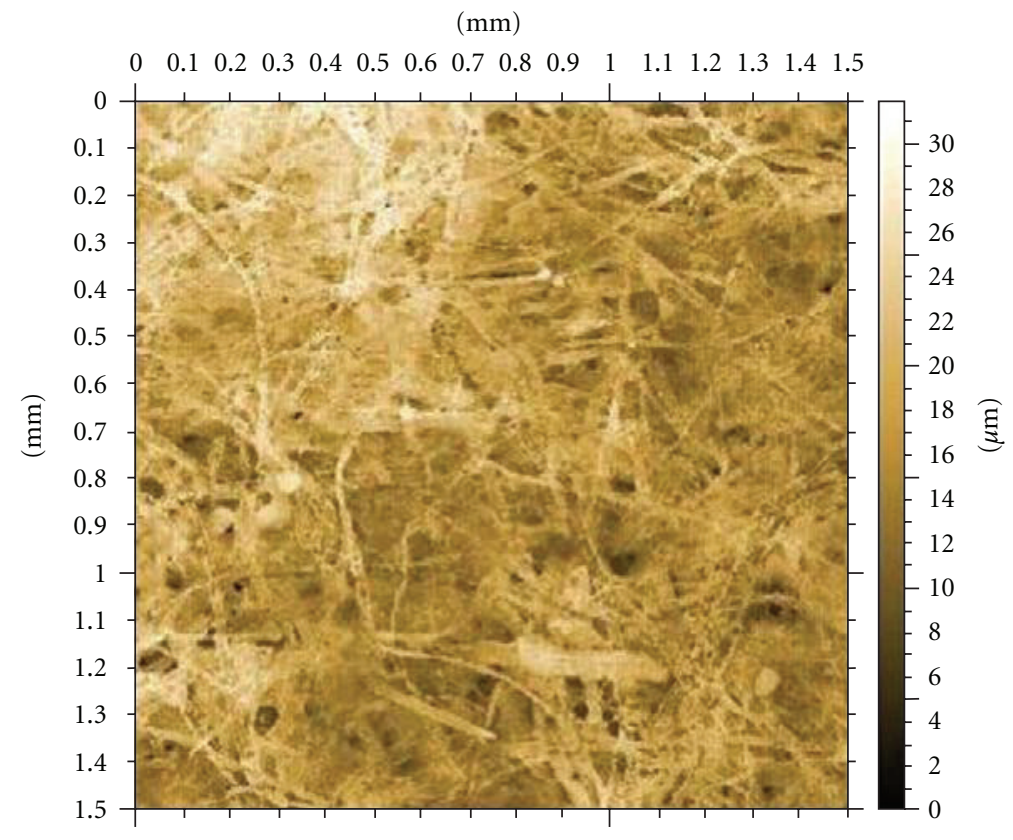

Figure 25: 2D surface of rough paper. Figure is taken from [135].

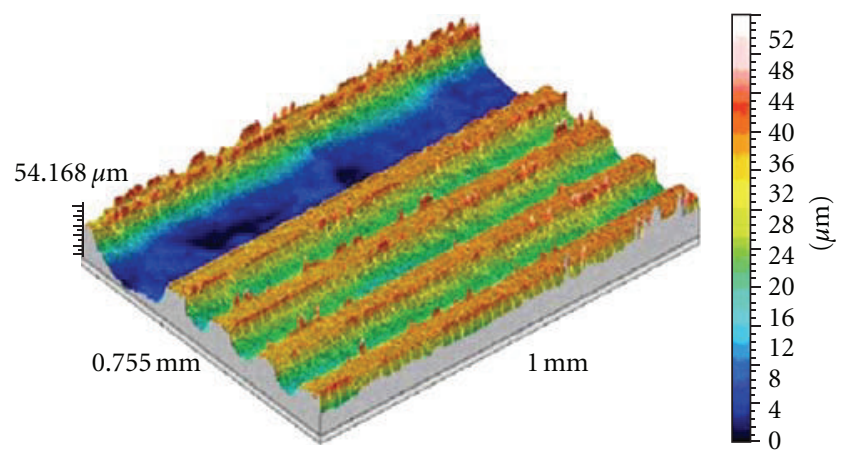

FIGURE 26: 3D topography image of a banknote [39].

on banknote surfaces, three-dimensional applied work is also plotted. Special marks make difficult to counterfeit banknotes and allow to evaluate their authenticity. An image of the $50 €$ banknote fragment is shown in Figure 26.

The next application is the analysis of the surface of shot fired from the gun, which is used for gun identification [115]. In this branch, the NIST leads a program of model gun cartridge production, where it is fired from each gun directly after manufacturing and on which each gun leaves individual marks [116]. This cartridge is used for the identification of guns, because the marks of the gun barrel are impressed on its surface. The marks are measured as the roughness of each gun, which is as adequate as identification of fingerprints for people [117].

Research applications of surface topography in medicine and bioengineering can be without hesitation admitted as being a real triumph of the end of the last millennium and the beginning of the new one. A review of applications from bioengineering has been described in [118, 119]. The surface topography of the prosthesis that is used with the biological human system has been discussed. Bones and implants surface analysis is another important medicine application, since roughness of the implants surface has a notable influence on the force of the connection and the reaction of tissues in the joint area between bone and implant, and even on the behavior of germs in bone tissue. While, in 1995 research work showed that patients undergoing revision orthopedic surgery need to stay longer at the hospital and the time in the operating room is significantly higher compared with primary surgery [119], recent work has been done to study the contact homogeneity between implanted biomaterial and the cortical bone using SEM technique, see Figure 27. It was observed that the biomimetic-hydroxyapatite-(BHA-) coating layer was not fully covering the cylinders and therefore the implants were once more immersed in PBS (phosphate buffered saline) for additional 7 days at $37^{\circ} \mathrm{C}$. The bone/implant contact was calculated from the images by measuring the contact length along the periphery of the sides and bottom of the implants, Figure 27(b). Quantitative analysis was performed on the SEM images using software (LeicaQwin) to calculate the bone density within the nearest $200 \mu \mathrm{m}$ of tissue surrounding the implants. Areas of soft tissue and bone along the sides and bottom of implants were determined from the difference in contrast between the two areas.

In new study, the advanced CT reconstruction technique for measuring an instantaneous 3D distribution of chemiluminescence of a turbulent premixed flame has been accomplished for a turbulent propane-air rich premixed flame. These displays help us to recognize the detail and total shape of objective flame. It can be clearly seen that the CT technique is able to clearly distinguish between 


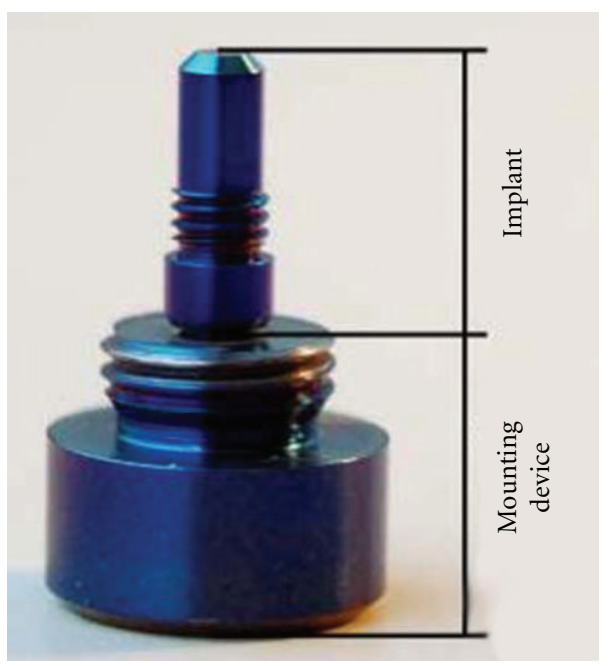

(a)

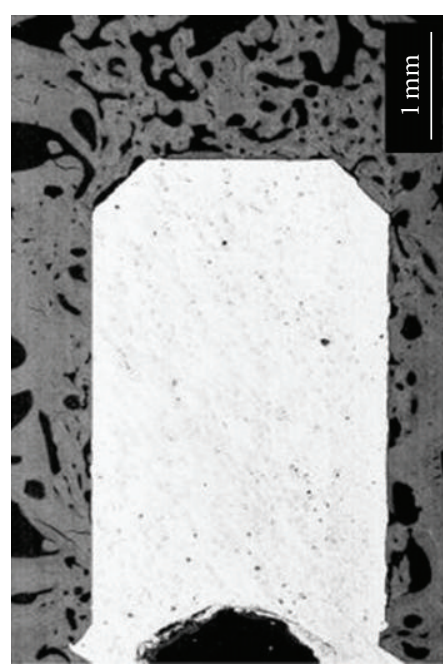

(b)

FIgURE 27: Photograph and SEM images of implanted cylindrical pin biomaterial. Figure is taken from [136]. (a) Implant cylindrical pin, the screw at the top used to fixate the implant in the cortical bone. (b) SEM image shows bone around the entire implanted biomaterial.

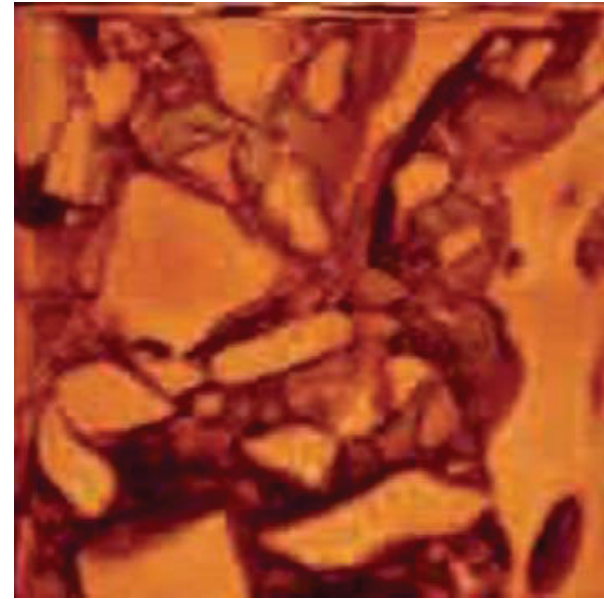

(a) Xenograft (left)

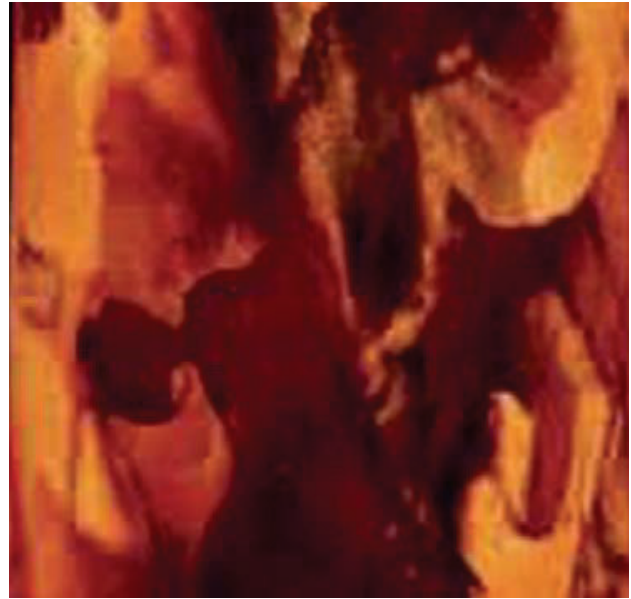

(b) Bioscaffold (right)

Figure 28: Micro-CT 3D render image of bioscaffold regenerated bone sample. Figure is taken from [120].

the dental bone extracted from the two different sockets [120]. The socket with the bioscaffold had natural bone with the osteocytes while the bone sample from the socket which had Xenograft shows lack of osteocytes. In addition, sample grafted with bioscaffold shows greater presence of soft tissues in Figure 28.

\section{Uncertainty}

Uncertainty in measurement results of any metrological technique is considered as an important guide to the quality of the measurement procedure. One of the problems in evaluation of dimensional and surface measurements is that different factors affecting the total uncertainty cannot be separated. One can generally distinguish two types of uncertainty. The first one determines the systematic errors, which can be corrected theoretically. The second one determines the random errors. Recent research works involving the uncertainty resulting from measurement operations and their estimation in both contact and non-contact measurement methods have been carried out [121-125].

In CMM, Marsh et al. [121] compared the multistep method with the Donaldson reversal method to test the ability of the methods to separate errors at the nanometer level. Nafi et al. [122] studied the uncertainty in measurement of CMM-based implementation of the multistep method for the separation of machine and reference sphere errors on one side and triggering probe and probe tip errors on the other. Instead of a spindle rotating, the probe moves with the aid of the machine linear axes for each measurement. This method has been tested in the laboratory and the results were confirmed by measuring separately 
the probe errors and the machine errors. A good agreement between characteristics of the probe pretravel shape was obtained between the proposed method and the independent measuring techniques. The work presented by Giusca et al. [123] shows the uncertainty evaluation associated with the NPL areal new CMM. A sound mathematical model has been developed to describe the CMM geometry and functionality. Based on this model the uncertainty associated with the point coordinate measurement has been evaluated using a Monte Carlo technique, similar to the "virtual CMM" method. The Monte Carlo approach is based on using an input-output model and the probability distributions assigned to the input quantities in the model to evaluate the output quantity uncertainty. The main conclusion is that the NPL areal instrument is capable of measuring the relative position of a point on a surface with nanometer scale uncertainties. Intrinsic properties of the interferometers do not contribute significantly to the uncertainties associated with the point coordinate measured. In near future, to calibrate advanced accurate CMMs, further refinement of the mechanical parts of the laser tracking interferometer has to be introduced.

The uncertainty in the multisensorial measurement system consists of an optical light-section system and a shading system has been studied [124]. This work has been installed and assists to monitor the process in real time better than before and leads to superior product quality and less rework at the end customer of the semifinished products.

In spite of the information given by the previous studies of AFM tip-sample interactions, some problems are still unresolved in evaluating the uncertainty. An algorithm for the evaluation of the error and uncertainty contribution has been tested and developed with experimental results obtained from four step heights [125]. The application of the algorithm in this study is given for an aluminum rolling machine used in imprint lithography. Global uncertainty budget in AFM measurements including calibration certificate, repeatability, orthogonally error, temperature drift and tip-sample angle parameters of the AFM measurements has been estimated. Various methods for evaluation of the uncertainty budget in measurement for dimensional measuring techniques can be found elsewhere $[13,26-37,51$, $123,125,126]$.

\section{Conclusion}

In this paper, a review of advanced measuring techniques in the dimensional and surface metrology and their applications from micro- to nanoscale has been presented in detail. Recent progress and future trends under development in this area have been presented and discussed. The following are the major observations from the literature.

(1) The advanced nanomeasuring techniques are very important in the surface metrology for understanding the properties of the objects quality, design purposes, diagnostics, and high throughput screening. Both contact and non-contact metrology techniques are available methods for objects characterization.
(2) It is clear that the mechanical stylus instrument is viewed as the fundamental method of measurements and the mechanical surface analyses. However now, probe-scanning techniques are capable of characterizing the case of geometric surfaces in 3D.

(3) Optical nanomeasuring techniques have been reviewed recently because of their important role. For accurate topographic measurements with optical methods, there are a number of issues to be considered as slope limitations, smoothing, focus condition, stray light, surface detection algorithms, shadowing, and multiple scattering.

(4) Some important issues need urgent attention: acquisition of detected data in an economical and efficient way, filtering of noisy data, and extracting the statistical feature of the data.

(5) The hybrid opto-tactile probing system and nanoultraprecision techniques need more research to reach high accuracy in the feature.

(6) Multiintegrated microscope as a combination between atomic force microscope and 3D optical profilometer needs advanced research to reach combine advantages in the future.

(7) The overlapping between dimensional measuring techniques needs new investigation in the context of presented advanced technology.

(8) With tremendous progress, development of ISO standards becomes an essential requirement within the recent time. This may require the support and establishment of new technical committees.

If these issues are addressed, the engineering industrial application will become easy and fruitful task.

\section{References}

[1] S. H. R. Ali, "Advanced measuring techniques in dimensional and surface metrology," in Proceedings of the 9th International Scientific Conference of Coordinate Measuring Technique (IMEKO-CT14), Bielsko-Biała, Poland, April 2012.

[2] T. V. Vorburger, H.-G. Rhee, T. B. Renegar, J.-F. Song, and A. Zheng, "Comparison of optical and stylus methods for measurement of surface texture," International Journal of Advanced Manufacturing Technology, vol. 33, no. 1-2, pp. 110-118, 2007.

[3] ISO Committee Draft 25178-6, Geometrical product specification (GPS)-Surface texture: areal-Part 6: Classification of methods for measuring surface texture, 2007.

[4] T. Vorburger, "ISO Standards for surface texture: update," NIST, 2008, http://cstools.asme.org/csconnect/pdf/CommitteeFiles/29042.pdf.

[5] J. A. Bosch, Coordinate Measuring Machines and Systems, Marcel Dekker, New York, NY, USA, 1995.

[6] J. A. Bosch, Coordinate Measuring Machines and Systems, Marcel Dekker, 1st edition, 1995.

[7] J. Gou, Theory and algorithms for coordinate metrology [Ph.D. thesis], Hong Kong University of Science and Technology, 1999. 
[8] Courtesy Xspect Solutions, Coordinate measuring machine (CMM) History, http://www.tusdec.org.pk/projects/gtdmc/ solutions/tutorials/in/in-7.pdf.

[9] http://www.caliperinc.com/new_page_8.htm.

[10] J. Ni and F. Waldele, "Coordinate measuring machine," in Coordinate Measuring Machine, J. A. Bosch, Ed., chapter 2, Marcel Dekker, New York, NY, USA, 1995.

[11] S. H. R. Ali, "The influence of fitting algorithm and scanning speed on roundness error for $50 \mathrm{~mm}$ standard ring measurement using CMM," Journal of Metrology \& Measurement Systems, vol. 15, no. 1, pp. 31-53, 2008.

[12] International Standards: Geometrical Product Specifications (GPS)-Acceptance and Reverification Tests for Coordinate Measuring Machines (CMM)-Part 2: CMMs used for Measuring Size, ISO, 10360-2, 2001.

[13] S. D. Phillips, B. Borchardt, W. T. Estler, and J. Buttress, "The estimation of measurement uncertainty of small circular features measured by coordinate measuring machines," Precision Engineering, vol. 22, no. 2, pp. 87-97, 1998.

[14] S. H. R. Ali, "Two dimensional model of CMM probing system," Journal of Automation, Mobile Robotics \& Intelligent Systems, vol. 4, no. 2, pp. 3-7, 2010, http://www.jamris.org/ issue_02_2010.php.

[15] S. H. R. Ali, "Probing system characteristics in coordinate metrology," Measurement Science Review, vol. 10, no. 4, pp. 120-129, 2010.

[16] G. Hermann, "Geometric error correction in coordinate measurement," Acta Polytechnica Hungarica, vol. 4, no. 1, pp. 47-62, 2007.

[17] J. J. Park, K. Kwon, and N. Cho, "Development of a coordinate measuring machine (CMM) touch probe using a multiaxis force sensor," Measurement Science and Technology, vol. 17, no. 9, pp. 2380-2386, 2006.

[18] A. Woźniak and M. Dobosz, "Influence of measured objects parameters on CMM touch trigger probe accuracy of probing," Precision Engineering, vol. 29, no. 3, pp. 290-297, 2005.

[19] A. Kasparaitis and A. Šukys, "Dynamic errors of CMM probes," Solid State Phenomena, vol. 113, pp. 477-482, 2006.

[20] Y. Wu, S. Liu, and G. Zhang, "Improvement of coordinate measuring machine probing accessibility," Precision Engineering, vol. 28, no. 1, pp. 89-94, 2004.

[21] J.-A. Yagüe, J.-A. Albajez, J. Veĺazquez, and J.-J. Aguilar, "A new out-of-machine calibration technique for passive contact analog probes," Measurement, vol. 42, no. 3, pp. 346$357,2009$.

[22] A. Woźniak, J. R. R. Mayer, and M. Bałaziński, "Stylus tip envelop method: corrected measured point determination in high definition coordinate metrology," International Journal of Advanced Manufacturing Technology, vol. 42, no. 5-6, pp. 505-514, 2009.

[23] M. Antonetti, M. Barloscio, A. Rossi, and M. Lanzetta, "Fast genetic algorithm for roundness evaluation by the minimum zone tolerance (MZT) method," Measurement, vol. 44, no. 7, pp. 1243-1252, 2011.

[24] Zeiss Calypso Navigator, CMM operation instructions and training manual, Revision 4.0, Germany, 2004.

[25] A. Garces, D. Huser-Teuchert, T. Pfeifer, P. Scharsich, F. Torres-Leza, and E. Trapet, "Performance test procedures for optical coordinate measuring probes," report on contract 3319/1/0/159/89/8-BCR-D(30), European Communities, Brussels, Belgium, 1993.

[26] http://www.meopta.com/en/o-inspect-1404042583.html.
[27] Z. G. Fei, J. J. Guo, X. J. Ma, and D. Z. Gao, "A novel type compact five-coordinate measuring machine with laser and CCD compound probe," Measurement, vol. 44, no. 9, pp. 1598-1605, 2011.

[28] J. Sładek, P. M. Błaszczyk, M. Kupiec, and R. Sitnik, "The hybrid contact-optical coordinate measuring system," Measurement, vol. 44, no. 3, pp. 503-510, 2011.

[29] L. Xiuming and S. Zhaoyao, "Application of convex hull in the assessment of roundness error," International Journal of Machine Tools and Manufacture, vol. 48, no. 6, pp. 711-714, 2008.

[30] T.-H. Sun, "Applying particle swarm optimization algorithm to roundness measurement," Expert Systems with Applications, vol. 36, no. 2, part 2, pp. 3428-3438, 2009.

[31] D. Bogomolov, V. Poroshin, A. Kostyuk, and V. Radygin, "High precision PC based measurement systems for complex analysis of roundness and waviness," Advanced Engineering, vol. 4, no. 1, pp. 5-8, 2010.

[32] http://www.rosebank-eng.com.au/news latest_news TR365 .html.

[33] Talyround Measuring Technique, TR-73, http://www.npl .co.uk/science-technology/dimensional/services/high-accuracy-roundness-measurement.

[34] http://taylor-hobson.virtualsite.co.uk/ultraroundness.htm.

[35] W. Gao and S. Kiyono, "On-machine roundness measurement of cylindrical work pieces by the combined three-point method," Measurement, vol. 21, no. 4, pp. 147-156, 1997.

[36] S. Mekid and K. Vacharanukul, "In-process out-ofroundness measurement probe for turned workpieces," Measurement, vol. 44, no. 4, pp. 762-766, 2011.

[37] R. Verma and J. Raja, "Characterization of engineered surfaces," Journal of Physics, vol. 13, no. 1, pp. 5-8, 2005.

[38] E. J. Abbott and F. A. Firestone, "Specifying surface quality," Mechanical Engineering, vol. 55, pp. 569-572, 1933.

[39] T. G. Mathia, P. Pawlus, and M. Wieczorowski, "Recent trends in surface metrology," Wear, vol. 271, no. 3-4, pp. 494-508, 2011.

[40] 8000-T Nanoscan, Hommel-Etamic Jenoptik, Schwenningen, 2008, http://www.jenoptik.com/Internet_EN_HOMMEL-ETAMIC_T8000_wavemove.

[41] E. Peiner, "Compliant tactile sensors for high-aspect-ratio form metrology," in Sensors, Focus on Tactile, Force and Stress Sensors, J. Gerardo Rocha and S. Lanceros-Mendez, Eds., Chapter 21, p. 444, I-Tech, Vienna, Austria, 2008.

[42] E. Peiner, M. Balke, and L. Doering, "Form measurement inside fuel injector nozzle spray holes," Microelectronic Engineering, vol. 86, no. 4-6, pp. 984-986, 2009.

[43] M. Wieczorowski, "Spiral sampling as a fast way of data acquisition in surface topography," International Journal of Machine Tools and Manufacture, vol. 41, no. 13-14, pp. 20172022, 2001.

[44] J. Song, "the effect of gaussian filter long wavelength cutoff $\lambda \mathrm{c}$ in topography measurements and comparisons," in Proceedings of the 21st Annual Meeting of the American Society for Precision Engineering, pp. 387-390, Monterey, Calif, USA, October 2006.

[45] J. M. Bennett, "Overview: sensitive techniques for surface measurement and characterization," in Commercial Applications of Precision Manufacturing at the Sub-Micron Level, vol. 1573 of Proceedings of SPIE, pp. 152-158, April 1992. 
[46] J. M. Bennett, "Recent developments in surface roughness characterization," Measurement Science and Technology, vol. 3, no. 12, pp. 1119-1127, 1992.

[47] H. J. Tiziani, "Optical methods for precision measurements-an invited paper," Optical and Quantum Electronics, vol. 21, no. 4, pp. 253-282, 1989.

[48] K. Leonhardt, K.-H. Rippert, and H. J. Tiziani, "Optical methods of measuring rough surfaces," in Surface Measurement and Characterization, vol. 1009 of Proceedings of SPIE, pp. 22-29, September 1988.

[49] C. J. Tay, S. H. Wang, C. Quan, and H. M. Shang, "In situ surface roughness measurement using a laser scattering method," Optics Communications, vol. 218, no. 1-3, pp. 1-10, 2003.

[50] S. Wang, Y. H. Tian, C. J. Tay, and C. Quan, "Development of a laser-scattering-based probe for on-line measurement of surface roughness," Applied Optics, vol. 42, no. 7, pp. 13181324, 2003.

[51] UKAS, "Measurement uncertainty definitions," http://www .ukas.com/technical-information/publications-and-tech-articles/technical/technical-uncertain.asp.

[52] A. Harasaki, J. Schmit, and J. C. Wyant, "Improved verticalscanning interferometry," Applied Optics, vol. 39, no. 13, pp. 2107-2115, 2000.

[53] B. Bhushan, J. C. Wyant, and C. L. Koliopoulos, "Measurement of surface topography of magnetic tapes by Mirau interferometry," Applied Optics, vol. 24, no. 10, pp. 14891497, 1985.

[54] J. E. Greivenkamp and J. H. Bruning, "Phase-shifting interferometry," in Optical Shop Testing, D. Malacara, Ed., pp. 501-598, John Wiley \& Sons, New York, NY, USA, 1992.

[55] Y. N. Denisyuk, "On the reproduction of the optical properties of an object by the wave field of its scattered radiation. I," Optics and Spectroscopy, vol. 15, p. 279, 1963.

[56] Y. N. Denisyuk, "On the reproduction of the optical properties of an object by the wave field of its scattered radiation. II," Optics and Spectroscopy, vol. 18, p. 152, 1965.

[57] B. J. Chang, R. C. Alferness, and E. N. Leith, "Space-invariant achromatic grating interferometers: theory," Applied Optics, vol. 14, no. 7, pp. 1592-1600, 1975.

[58] E. N. Leith and G. J. Swanson, "Achromatic interferometers for white light optical processing and holography," Applied Optics, vol. 19, no. 4, pp. 638-644, 1980.

[59] Y.-S. Cheng and E. N. Leith, "Successive fourier transformation with an achromatic interferometer," Applied Optics, vol. 23, no. 22, pp. 4029-4033, 1984.

[60] E. N. Leith and R. R. Hershey, "Transfer functions and spatial filtering in grating interferometers," Applied Optics, vol. 24, no. 2, pp. 237-239, 1985.

[61] J. C. Wyant, C. L. Koliopoulos, B. Bhushan, and O. E. George, "An optical profilometer for surface characterization of magnetic media," ASLE Transactions, vol. 27, no. 2, pp. 101-113, 1984.

[62] P. F. Forman, “The ZYGO interferometer system," in Interferometry, vol. 129 of Proceedings of SPIE, pp. 41-48, August 1979.

[63] L. Deck and P. de Groot, "High-speed noncontact profiler based on scanning white-light interferometry," Applied Optics, vol. 33, no. 31, pp. 7334-7338, 1994.

[64] J. Schmit and A. Olszak, "High-precision shape measurement by white-light interferometry with real-time scanner error correction," Applied Optics, vol. 41, no. 28, pp. 5943-5950, 2002.

[65] T. V. Vorburger, H.-G. Rhee, T. B. Renegar, J.-F. Song, and A. Zheng, "Comparison of optical and stylus methods for measurement of surface texture," International Journal of Advanced Manufacturing Technology, vol. 33, no. 1-2, pp. 110-118, 2007.

[66] J. C. Wyant, "White light extended source shearing interferometer," Applied Optics, vol. 13, no. 1, pp. 200-202, 1974.

[67] Y.-Y. Cheng and J. C. Wyant, "Two-wavelength phase shifting interferometry," Applied Optics, vol. 23, no. 24, pp. 45394543, 1984.

[68] Y. Y. Cheng and J. C. Wyant, "Multiple-wavelength phaseshifting interferometry," Applied Optics, vol. 24, no. 6, pp. 804-807, 1985.

[69] Optical Topography Measurement and Material Characterisation of Alu Cylinder Faces, http://www.breitmeier .com/component/content/article/119-wissen\#fig6.

[70] M. Conroy and J. Armstrong, "A comparison of surface metrology techniques," Journal of Physics, vol. 13, no. 13, pp. 458-465, 2005.

[71] S. Ma, C. Quan, R. Zhu, C. J. Tay, and L. Chen, "Surface profile measurement in white-light scanning interferometry using a three-chip color CCD," Applied Optics, vol. 50, no. 15, pp. 2246-2254, 2011.

[72] S. Ma, C. Quan, R. Zhu, C. J. Tay, L. Chen, and Z. Gao, "Micro-profile measurement based on windowed Fourier transform in white-light scanning interferometry," Optics Communications, vol. 284, no. 10-11, pp. 2488-2493, 2011.

[73] Zygo-3D, http://www.ims.uconn.edu/facilities/surface_analysis.html.

[74] M. Minsky, Microscopy Apparatus, U.S. Patent No. 3013467, 19, December 1961.

[75] M. Minsky, "Memoir on inventing the confocal scanning microscope," Scanning, vol. 10, no. 4, pp. 128-138, 1988.

[76] U. Schnars and W. P. O. Jüptner, "Digital recording and numerical reconstruction of holograms," Measurement Science and Technology, vol. 13, no. 9, pp. R85-R101, 2002.

[77] Y. Awatsuji, T. Koyama, T. Tahara et al., "Parallel opticalpath-length-shifting digital holography," Applied Optics, vol. 48, no. 34, pp. H160-H167, 2009.

[78] N. F. A-Maaboud, M. S. El-Bahrawi, and F. Abdel-Aziz, "Digital holography in flatness and crack investigation," Metrology and Measurement Systems, vol. 17, no. 4, pp. 583588, 2010.

[79] X. Yu, M. Cross, C. Liu, D. C. Clark, D. T. Haynie, and K. K. Kim, "Quantitative imaging and measurement of cellsubstrate surface deformation by digital holography," Journal of Modern Optics, vol. 59, no. 18, pp. 1591-1598, 2012.

[80] A. Vilalta-Clemente and K. Gloystein, Principles of atomic force microscopy (AFM), based on the lecture of Prof. Nikos, Frangis Aristotle University, Thessaloniki, Greece, Physics of Advanced Materials Winter School, 2008, http://www.mansic.eu/documents/PAM1/Frangis.pdf.

[81] Ernst Ruska, Ernst Ruska Autobiography, Nobel foundation, 1986, http://nobelprize.org/nobel_prizes/physics/laureates/ 1986/ruska-autobio.html.

[82] G. Binnig, C. F. Quate, and C. Gerber, "Atomic force microscope," Physical Review Letters, vol. 56, no. 9, pp. 930933, 1986. 
[83] The principles of Atomic Force Microscopy (AFM), https://www.uclan.ac.uk/schools/computing_engineeringphysical/jost/files/AFM.pdf.

[84] Difference between AFM and STM, 2011, http://www .differencebetween.net/technology/difference-between-afmand-stm/.

[85] G. Binning, H. Rohrer, E. Weibel et al., "Surface studies by scanning tunneling microscopy," Physical Review Letters, vol. 49, no. 1, pp. 57-61, 1982.

[86] H.-Y. Nie, "Scanning probe techniques," http://publish .uwo.ca/ hnie/spmman.html\#c-afm.

[87] M. Simon, I. Tiseanu, and C. Sauerwein, "Advanced computed tomography system for the inspection of large aluminium car bodies," ECNDT, 2006.

[88] V. Andreu, B. Georgi, H. Lettenbauer, and J. A. Yague, "Analysis of the error sources of a Computer Tomography Machine," pp. 1-10, 2009, http://www.iberprecis.es/docs/Paper_CT.pdf.

[89] S. Kasperl, J. Hiller, and M. Krumm, "Computed tomography metrology in industrial research \& development," in Proceedings of the International Symposium on NDT in Aerospace, pp. 1-8, Fürth, Germany, December 2008.

[90] M. Bartscher, U. Neuschaefer-Rube, and F. Wäldele, "Computed tomography-a highly potential tool for industrial quality control and production near measurements," VDI Berichte, vol. 1860, pp. 477-796, 2004.

[91] M. Bartscher, U. Hilpert, J. Goebbels, and G. Weidemann, "Enhancement and proof of accuracy of industrial computed tomography (CT) measurements," CIRP Annals, vol. 56, no. 1, pp. 495-498, 2007.

[92] M. Stedman, "Limits of surface measurement by optical probes," in Surface Measurement and Characterisation, vol. 1009 of Proceedings of SPIE, pp. 62-67, Hamburg, Germany, September 1988.

[93] M. Stedman and K. Lindsey, "Limits of surface measurement by stylus instruments," in Surface Measurement and Characterization, vol. 1009 of Proceedings of SPIE, pp. 56-61, Hamburg, Germany, September 1988.

[94] H. Schwenke, U. Neuschaefer-Rube, T. Pfeifer, and H. Kunzmann, "Optical methods for dimensional metrology in production engineering," CIRP Annals, vol. 51, no. 2, pp. 685-699, 2002.

[95] S. H. R. Ali, M. Kamal Bedewy, and S. Z. Zahwi, "Dimensional inspection of overhauled automotive water-cooled diesel engines," in Proceedings of the 9th International Conference on Production Engineering, Design, and Control (PEDAC '09), pp. 10-12, Alexandria, Egypt, February 2009.

[96] S. H. R. Ali, H. H. Mohamed, and M. K. Bedewy, "Identifying cylinder liner wear using precise coordinate measurements," International Journal of Precision Engineering and Manufacturing, vol. 10, no. 5, pp. 19-25, 2009.

[97] A. V. Sreenath and N. Raman, "Running-in wear of a compression ignition engine: factors influencing the conformance between cylinder liner and piston rings," Wear, vol. 38, no. 2, pp. 271-289, 1976.

[98] A. Spencer, A. Almqvist, and R. Larsson, "A semideterministic texture-roughness model of the piston ringcylinder liner contact," Proceedings of the Institution of Mechanical Engineers J, vol. 225, no. 6, pp. 551-555, 2011.

[99] L. Rapoport, A. Moskovith, V. Perfilyev et al., "Friction and wear of $\mathrm{MoS}_{2}$ films on laser textured steel surfaces," in Proceedings of 13th Nordic Symposium on Tribology (NORDTRIB '08), Tampere, Finland, June 2008.

[100] W. Koszela, L. Galda, A. Dzierwa, and P. Pawlus, "The effect of surface texturing on seizure resistance of steel-bronze assembly," in Proceedings of the 36th Leeds-Lyon Symposium on Tribology, Lyon, France, 2009.

[101] L. Galda, A. Dzierwa, J. Sep, and P. Pawlus, "The effect of oil pockets shape and distribution on seizure resistance in lubricated sliding," Tribology Letters, vol. 37, no. 2, pp. 301$311,2010$.

[102] E. Gualtieri, A. Borghi, L. Calabri, N. Pugno, and S. Valeri, "Increasing nanohardness and reducing friction of nitride steel by laser surface texturing," Tribology International, vol. 42, no. 5, pp. 699-705, 2009.

[103] L. Galda, P. Pawlus, and J. Sep, "Dimples shape and distribution effect on characteristics of Stribeck curve," Tribology International, vol. 42, no. 10, pp. 1505-1512, 2009.

[104] L. M. Vilhena, M. Sedlaček, B. Podgornik, J. Vižintin, A. Babnik, and J. Možina, "Surface texturing by pulsed Nd: YAG laser," Tribology International, vol. 42, no. 10, pp. 1496-1504, 2009.

[105] W. Koszela, P. Pawlus, and L. Galda, "The effect of oil pockets size and distribution on wear in lubricated sliding," Wear, vol. 263, no. 7-12, pp. 1585-1592, 2007.

[106] M. Mosleh and B. A. Khemet, "A surface texturing approach for cleaner disc brakes," Tribology and Lubrication Technology, vol. 62 , no. 12 , pp. 32-37, 2006.

[107] F.-P. Ninove, C. Rapiejko, and T. G. Mathia, “3D Morphological behaviour of heterogeneous model material in finishing abrasive process-case of nodular cast iron," in Advances in Coordinate Metrology, J. Sladek and W. Jakubiec, Eds., pp. 456-462, University of Bielsko-Biala, 2010.

[108] A. Spencer, I. Dobryden, N. Almqvist, A. Almqvist, and R. Larsson, "Surface characterization with functional parameters," submitted to. Tribology Transactions.

[109] S. H. R. Ali, M. A. Etman, B. S. Azzam, R. M. Rashad, and M. K. Bedewy, "Advanced nanometrology techniques of carbon nanotubes characterization," Metrology and Measurement Systems, vol. 15, no. 4, pp. 551-561, 2008.

[110] S. H. R. Ali, M. K. Bedewy, M. A. Etman, H. A. Khalil, and B. S. Azzam, "Morphology and properties of polymer matrix nanocomposites," International Journal of Metrology and Quality Systems, vol. 1, no. 1, pp. 33-39, 2010.

[111] Keyence, Keyence World Class Products for Sensing and Automation, 2008.

[112] C. Altin and I. Ozil, Applications of surface metrology to issues in art, Project report, Worcester polytechnic institute, 2008, http://www.wpi.edu/Pubs/E-project/Available/Eproject-042408-121857/unrestricted/IQP_ceren_ipek.pdf.

[113] J. Stor-Pellinen and M. Luukkala, "Paper roughness measurement using airborne ultrasound," Sensors and Actuators A, vol. 49, no. 1-2, pp. 37-40, 1995.

[114] J. S. Preston, N. J. Elton, J. C. Husband, J. Dalton, P. J. Heard, and G. C. Allen, "Investigation into the distribution of ink components on printed coated paper: part 1: optical and roughness considerations," Colloids and Surfaces A, vol. 205, no. 3, pp. 183-198, 2002.

[115] N. Senin, R. Groppetti, L. Garofano, P. Fratini, and M. Pierni, "Three-dimensional surface topography acquisition and analysis for firearm identification," Journal of Forensic Sciences, vol. 51, no. 2, pp. 282-295, 2006.

[116] E. P. Whitenton, C. Johnson, D. Kelley et al., "Manufacturing and quality control of the NIST reference material 8240 standard bullet," in Proceedings of the 18th Annual Meeting of the American Society for Precision Engineering, pp. 99-102, Portland, Ore, USA, 2003.

[117] J. F. Song, E. Whitenton, D. Kelley et al., "SRM 2460/2461 standard bullets and casings project," Journal of Research of 
the National Institute of Standards and Technology, vol. 109, no. 6, pp. 533-542, 2004.

[118] K. J. Stout and L. A. Blunt, "Application of 3-D topography to bio-engineering," International Journal of Machine Tools and Manufacture, vol. 35, no. 2, pp. 219-229, 1995.

[119] K. A. Krackow, D. S. Hungerford, C. J. Lavernia, M. K. Drakeford, A. K. Tsao, and A. Gittelsohn, "Revision and primary hip and knee arthroplasty: a cost analysis," Clinical Orthopaedics and Related Research, no. 311, pp. 136-141, 1995.

[120] R. Gunaseelan, V. Prabhu, B. Praveen et al., "Evaluation of bone quality in dental socket with two different approaches for ridge preservation using grey scale imaging and Novel Micro CT," Dental Asia, pp. 22-27, November/December 2010.

[121] E. Marsh, J. Couey, and R. Vallance, "Nanometer-level comparison of three spindle error motion separation techniques," Journal of Manufacturing Science and Engineering, vol. 128, no. 1, pp. 180-187, 2006.

[122] A. Nafi, J. R. R. Mayer, and A. Wozniak, "Novel CMM-based implementation of the multi-step method for the separation of machine and probe errors," Precision Engineering, vol. 35, no. 2, pp. 318-328, 2011.

[123] C. L. Giusca, R. K. Leach, and A. B. Forbes, "A virtual machine-based uncertainty evaluation for a traceable areal surface texture measuring instrument," Measurement, vol. 44, no. 5, pp. 988-993, 2011.

[124] J. Bernstein and A. Weckenmann, "User interface for optical multi-sensorial measurements at extruded profiles," Measurement, vol. 44, no. 1, pp. 202-210, 2011.

[125] H. González-Jorge, M. A. Fernández-López, J. L. Valencia, and S. Torres, "Uncertainty contribution of tip-sample angle to AFM lateral measurements," Precision Engineering, vol. 35, no. 1, pp. 164-172, 2011.

[126] R. Donker, I. Widdershoven, and H. Spaan, "Realization of Isara 400: a large measurement volume ultra-precision CMM," in Proceedings of the Asian Symposium for Precision Engineering and Nanotechnology, 2009.

[127] R. Ohisson, A topographic study of functional surfaces [Ph.D. thesis], Chalmers University of Technology, 1996.

[128] http://www.gum2012.fionastoreydesign.co.uk/confocal_ microscopy.html.

[129] Confocal white light sensor, Hommel-Etamic Jenoptik, Schwenningen, 2007.

[130] Craig Leising, Accurate Micropart Topography Using 3-D Metrology, 12/02/2010, http://www.qualitydigest.com/ inside/twitter-ed/accurate-micropart-topography-using-3d-metrology.html.

[131] http://www.phoenix-xray.com/en/company/technology/ principles_of_operation/principle_060.html.

[132] L. Brown and L. Blunt, "Surface metrology for the automotive industry," in Proceedings of the Inaugural Automotive Researchers' Conference, University of Huddersfield, January 2008, http://eprints.hud.ac.uk/4059/1/08AARC2008.pdf.

[133] Christopher, "Basic Elements of the Design and Selection of Surface Metrology Systems, 2006".

[134] C. A. Brown, The geometric nature of surface roughness and microwave transmission losses [Ph.D. thesis], http:// www.imapsne.net/archive/docs/Roughness-\%20Brown.pdf.

[135] M. Zecchino, "Characterizing surface quality: why average roughness is not enough," Advanced Materials and Processes, vol. 161, no. 3, pp. 25-28, 2003.
[136] J. Forsgren, U. Brohede, S. Piskounova et al., "In vivo evaluation of functionalized biomimetic hydroxyapatite for local delivery of active agents," Journal of Biomaterials and Nanobiotechnology, vol. 2, pp. 150-155, 2011. 

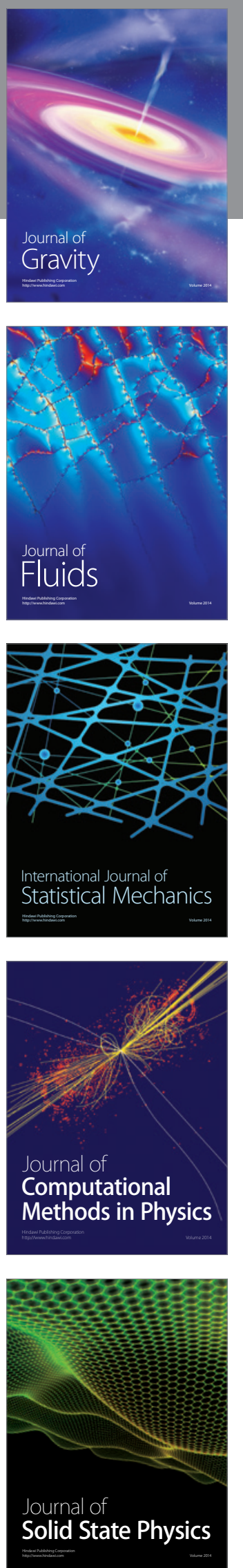
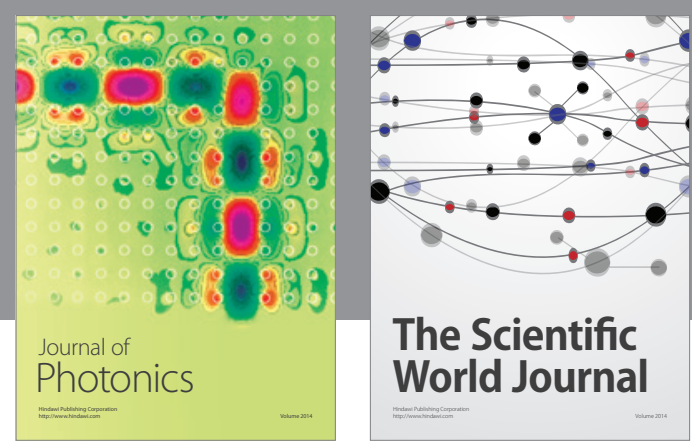

The Scientific World Journal

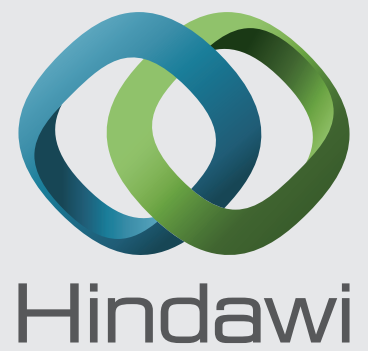

Submit your manuscripts at http://www.hindawi.com
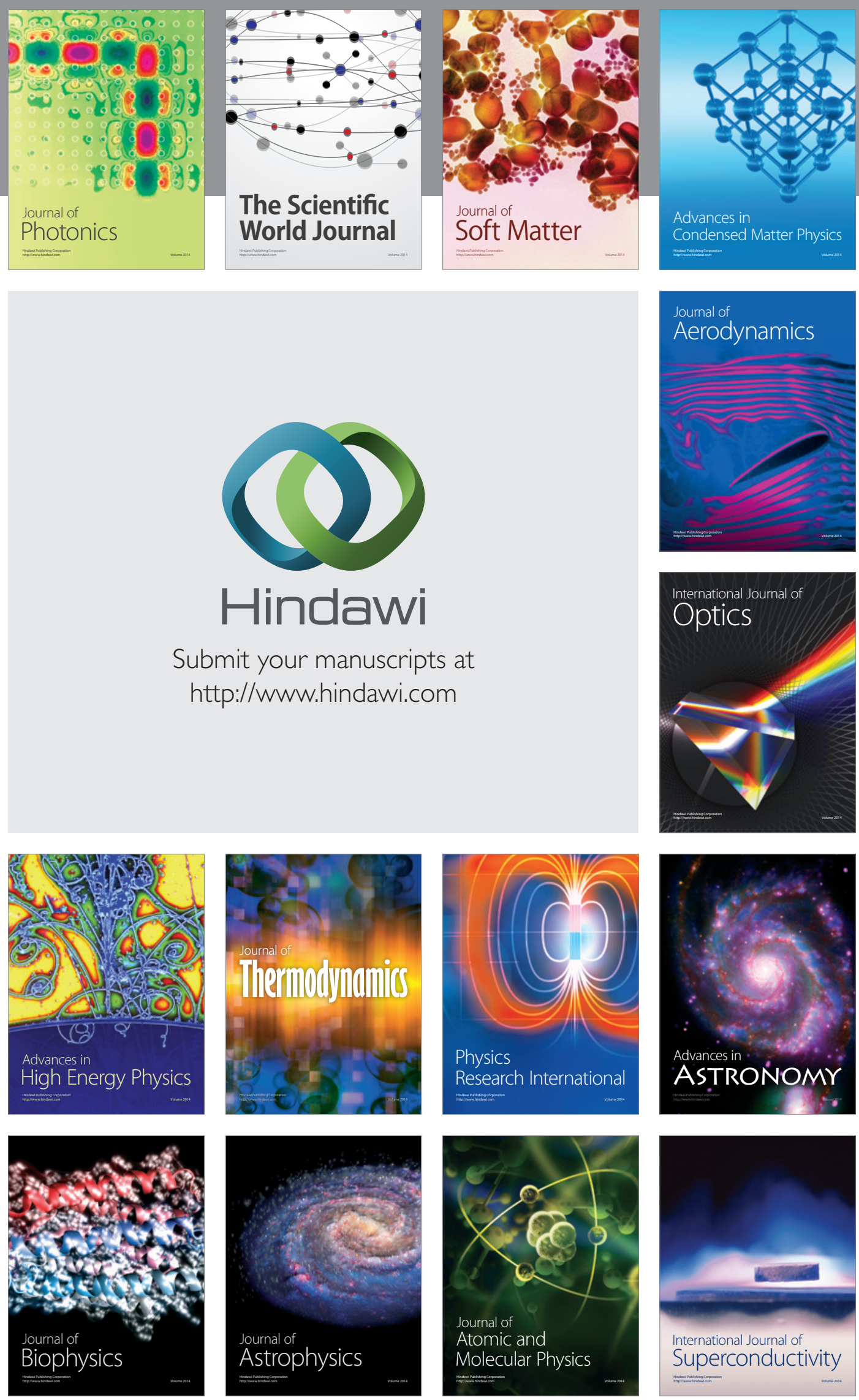
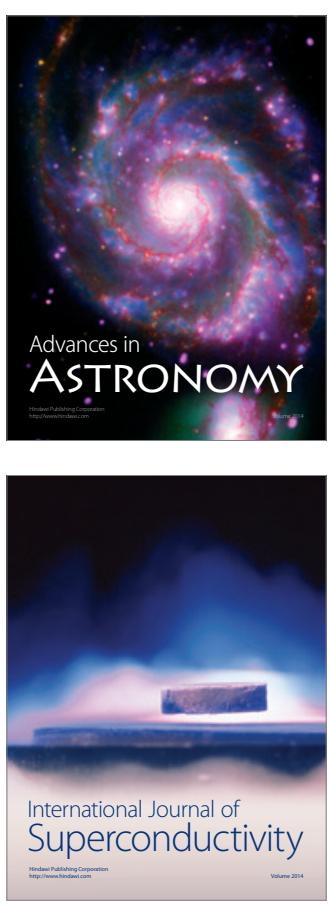